\title{
Metabolic Reprogramming and Reconstruction: Integration of Experimental and Computational Studies to Set the Path Forward in ADPKD
}

\author{
Roberto Pagliarini and Christine Podrini* \\ Molecular Basis of Cystic Kidney Disorders Unit, Division of Genetics and Cell Biology, IRCCS-San Raffaele Scientific \\ Institute, Milan, Italy
}

OPEN ACCESS

Edited by:

Katalin Susztak,

University of Pennsylvania,

United States

Reviewed by:

Peter Harris,

Mayo Clinic, United States

Christina Christoffersen,

Rigshospitalet, Denmark

${ }^{*}$ Correspondence:

Christine Podrin

Podrini.christine@hsr.it

Specialty section: This article was submitted to

Nephrology,

a section of the journal

Frontiers in Medicine

Received: 12 July 2021 Accepted: 25 October 2021 Published: 24 November 2021

Citation:

Pagliarini R and Podrini C (2021) Metabolic Reprogramming and

Reconstruction: Integration of Experimental and Computational Studies to Set the Path Forward in ADPKD. Front. Med. 8:740087. doi: 10.3389/fmed.2021.740087
Metabolic reprogramming is a key feature of Autosomal Dominant Polycystic Kidney Disease (ADPKD) characterized by changes in cellular pathways occurring in response to the pathological cell conditions. In ADPKD, a broad range of dysregulated pathways have been found. The studies supporting alterations in cell metabolism have shown that the metabolic preference for abnormal cystic growth is to utilize aerobic glycolysis, increasing glutamine uptake and reducing oxidative phosphorylation, consequently resulting in ADPKD cells shifting their energy to alternative energetic pathways. The mechanism behind the role of the polycystin proteins and how it leads to disease remains unclear, despite the identification of numerous signaling pathways. The integration of computational data analysis that accompanies experimental findings was pivotal in the identification of metabolic reprogramming in ADPKD. Here, we summarize the important results and argue that their exploitation may give further insights into the regulative mechanisms driving metabolic reprogramming in ADPKD. The aim of this review is to provide a comprehensive overview on metabolic focused studies and potential targets for treatment, and to propose that computational approaches could be instrumental in advancing this field of research.

Keywords: metabolism, systems biology, systems medicine, therapeutics, drug repositioning, ADPKD

\section{INTRODUCTION}

Autosomal Dominant Polycystic Kidney Disease (ADPKD) is a common monogenic disorder characterized by bilateral renal cyst formation and extra-renal manifestations. These manifestations include cysts in other organs, such as the liver and pancreas, as well as abnormalities including intracranial aneurysms. Worldwide around 12.5 million people suffer from ADPKD, and it is a common cause of end-stage renal disease (1). ADPKD is caused by mutations in either PKD1 (polycystin-1) or PKD2 (polycystin-2) genes, which account for almost 80 and 15\% of ADPKD cases, respectively. More recently, a third gene has been described, GANAB (which encodes neutral alpha-glucosidase $\mathrm{AB}$ ), which results in a milder renal phenotype and a more severe liver phenotype (2).

The polycystin1 ( $\mathrm{PC1}$ ) protein contains a large extracellular N-terminal region (3074 aa), 11 transmembrane domains (1032 aa), and a short intracellular C-terminal region (198 aa) $(3,4)$. PC1 interacts with PC2 through a coiled-coil domain in the C-terminal 
portion (5). The PC1 and PC2 complexes are detected in the ER membrane, the plasma membrane, exosomes, and the primary cilia, where they have been suggested to mediate calcium influx in response to fluid flow (6). Notwithstanding, the function of polycystin proteins in cilia and their role in calcium fluxes has been intensely debated (7).

The polycystin proteins have been shown to modulate numerous signaling pathways [please refer to this review for evidence of altered signaling pathways (8)] however their function remains unclear. In the last decade, research aimed at elucidating metabolic-related pathways in ADPKD has grown exponentially, and metabolic reprogramming is now considered a main feature of ADPKD (9-12). The number of researchers using multiple-omics (metabolomics, transcriptomics, genomics, and lipidomics) approaches is still growing and these studies have been pivotal in gaining substantial insights into the pathogenesis of PKD. There is a need for the scientific community to establish principles for data management, which can be challenging to interpret, unless efficiently analyzed. This huge amount of data creates more confusion and blurring than understanding.

One solution to overcome this problem is through the integration of Systems Biology approaches, which offer powerful abstraction tools to analyze biological reactions in a cell, providing a snapshot that is similar to its observable phenotype. Computational tools can be used not only to explore comprehensive molecular mechanisms but also to discover and test-novel therapeutic targets. For example, they were recently applied to identify novel drug candidates for the treatment of $\operatorname{ADPKD}(13,14)$. A possible System Biology workflow for the development of possible therapeutic targets that integrates wet-lab experiments, statistical and computational analysis, and System Medicine, is proposed in Figure 1. Systems Medicine represents a novel, more personalized, precise, and systematic, interdisciplinary approach in medicine. It involves the implementation of computational approach in medical concepts, research, and clinical practice, through iterative and feedback exchanges between clinicians, biologists, pharmacologists, bioinformaticians, and mathematicians.

\section{METABOLIC CHANGES IN ADPKD}

A broad range of metabolic pathways in ADPKD were described including: increased glycolysis, reduced fatty acid oxidation (FAO) and altered glutamine utilization with defective mitochondrial function. We describe the current biological findings and how mathematical modeling applied to biological data can be useful to gain further insights into the metabolic alterations.

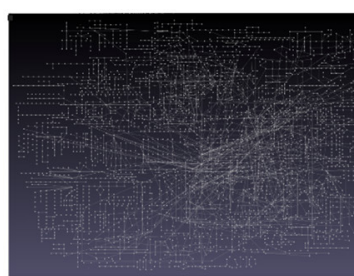

Initial hypothesis on metabolism

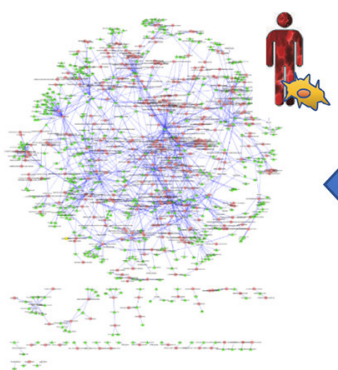

Human systems medicine
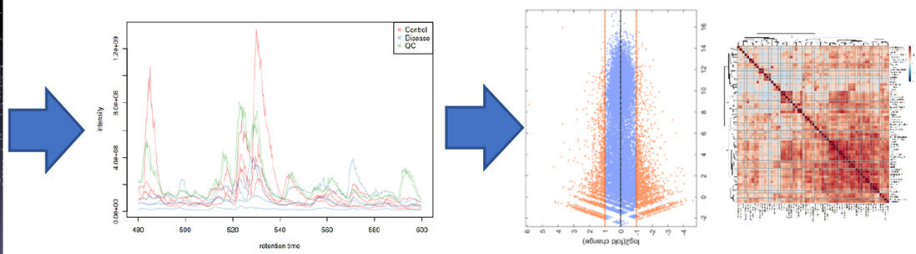

Wet-lab experiments

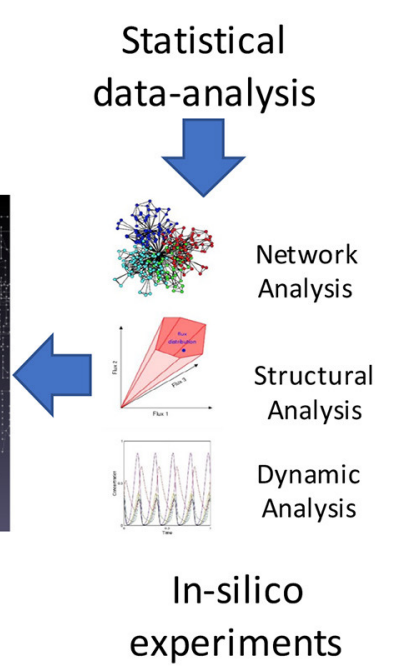

FIGURE 1 | The systems biology approach in ADPKD. Steps of the workflow for studying possible new therapeutics targets for ADPKD. The first step concerns the formulation of an initial hypothesis on possible changes in a metabolic network due to the disorder. In the second step, wet-lab experiments are employed to obtain omics data. The third step involves statistical analysis of the experimental data that will be used in the fourth phase to develop mathematical models for in-silico simulations. In the fifth step, in order to validate the initial hypothesis, the simulation results are mapped to the metabolic network. Finally, systems medicine is employed to propose new possible therapeutic targets. 
TABLE 1 | Characteristics of the included clinical trials.

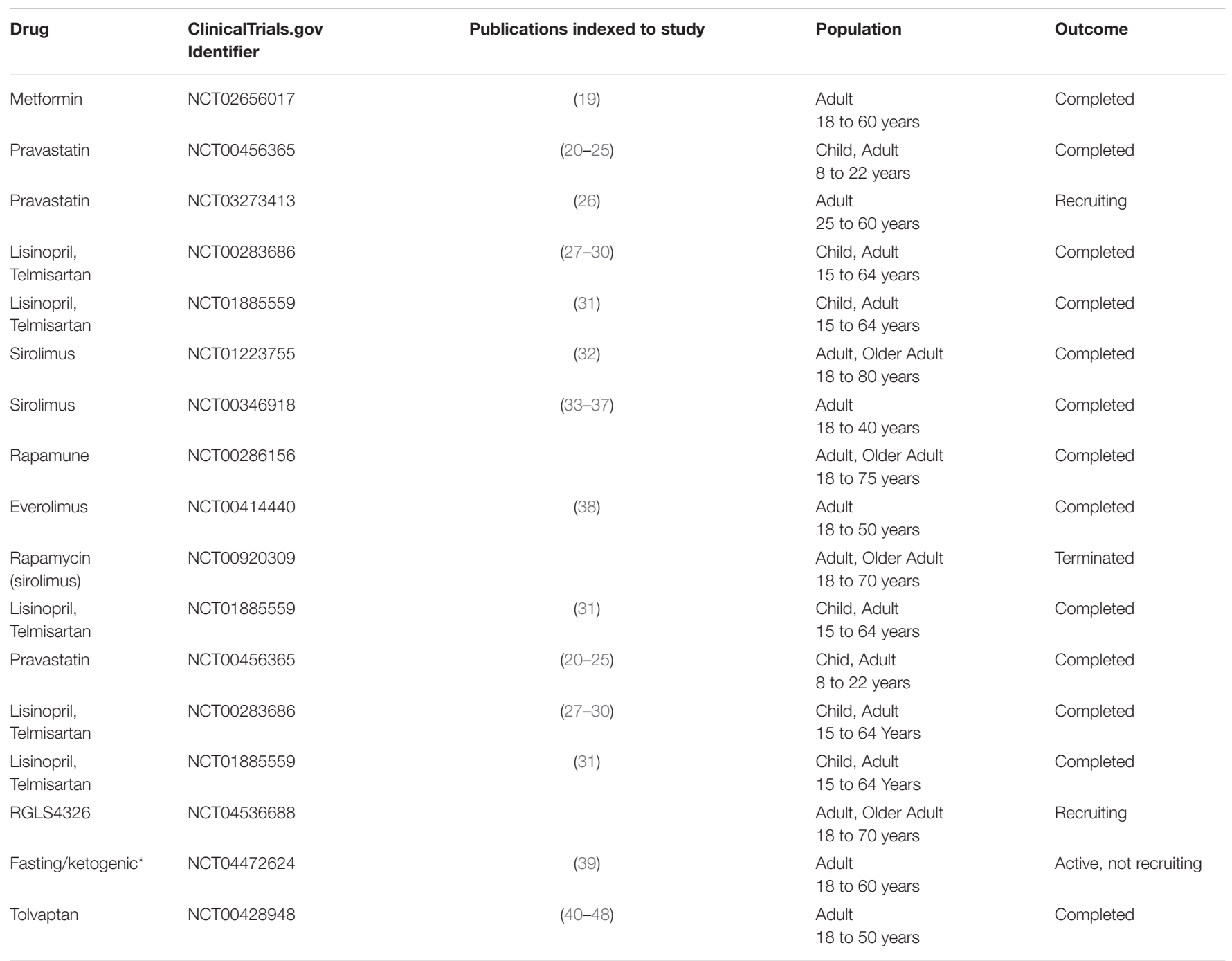

Order indicated as in the review. ${ }^{*}$ intervention/treatment.

\section{Lactate as an Energy Source}

One of the common features of cystic cells derived from murine models of ADPKD is that they exhibit increased glucose uptake and lactate accumulation (9). In $\mathrm{Pkd1}^{-/-}$cells, glucose is converted to pyruvate which is then reduced to lactate instead of being transported into mitochondria $(9,12)$. Metabolic tracing with ${ }^{13} \mathrm{C}_{6}$-glucose by NMR revealed a significant increase in lactate production in cystic kidneys compared to age-matched controls derived from an aggressive model (Ksp-Cre:Pkd1 $1^{\text {flox } /-}$ ) and a slowly progressive murine model (Tm-Cre:Pkd1 $1^{\text {flox/- }}$ ) of ADPKD (9). Increased glucose uptake was also found in $P k d 1$ mutant mouse embryonic kidney (MEK) cells compared with $P k d 1$ WT MEK cells (15). Further, an upregulation of glycolytic markers was observed $(9,15,16)$, and the glycolytic signature was confirmed in a subset of human microarray data and cystic kidneys derived from hypomorphic $P k d 1$ mutant mice $(9,12,17)$. A recent study investigated the cross-sectional association of urinary metabolic biomarkers with ADPKD (18) severity among the TAME-PKD trial participants at baseline (19) (Please refer to Table $\mathbf{1}$ for mentioned clinical trials). This study is the first evidence of human urine samples supporting that increasing ADPKD severity is associated with a metabolic shift toward increased aerobic glycolysis. Other studies on the analysis of biomarkers in ADPKD should follow as to determine the ability to detect if a particular biomarker changes with time and if the correlations may be associated with cellular damage rather than metabolic changes per se. The enhanced glycolysis, the so-called Warburg effect reminiscent of cancer cells (49), contributes to the metabolic re-wiring in ADPKD and is considered a prominent feature of this disease.

\section{Mitochondrial Abnormalities and ER Cross-Talk}

Mitochondria are the central organelles for metabolism and are the key players for energy production in the cells. Mitochondrial 
respiration has been reported to be altered in $P k d 1^{-/-}$proximal tubule cells (11). Indeed, the investigators demonstrated that oxygen levels regulate the localization and activity of PC1 by a prolyl hydroxylase domain-containing protein 3 (EGLN3). Furthermore, the study reported that the polycystin proteins localize in the mitochondria-associated membranes (MAMs), where they can mediate calcium signaling from the ER lumen to the mitochondrial matrix (11). PC2 depletion alters calcium transfer and decreases mitochondrial movement. This decrease is thought to be the result of an increased expression of the ER-mitochondrial tethering protein, mitofusin 2 (MFN2), which ultimate affecting calcium-mediated mitochondrial bioenergetics that contribute to cell proliferation (50). These findings collectively suggest that the polycystins are important regulators of mitochondrial function, but whether mitochondrial calcium and dynamics are disrupted in $P K D 1$ mutations warrants further investigation. A cleaved carboxyl-terminal fragment of PC1 has been proposed to accumulate in mitochondria, indicating that PC1 may directly modulate mitochondrial function (51). However, how this cleavage is involved in cyst formation or mitochondrial function is still unknown.

Morphologically, abnormal mitochondria were described in cyst-lining cells in an ADPKD mouse model (KspCre:Pkd1 flox/flox ) and in rats (Han:SPRD Cy/+) (52). This was accompanied by a reduction in mitochondrial number suggesting a decrease in mitochondrial mass in the cystic epithelia (52). In another study, the decrease in mitochondrial mass was found to be correlated with a reduced activity of mitochondrial respiratory enzymes and fragmentation of the mitochondrial network in the cystic epithelial of KspCre:Pkd1 $1^{f l o x} /-$ kidneys (53). The inhibition of mitochondrial function was shown to be mediated by miR-17- Ppara axis (54). The miR-17 inhibits OXPHOS and fatty acid oxidation, and its suppression improves mitochondrial function of cyst epithelia (54). PPAR $\gamma$, another member of the PPAR subfamily has been shown to be implicated in ADPKD pathogenesis. Moreover, treatment with PPAR $\gamma$ agonist rescues proliferation and retards cyst growth in rodent PKD models (55-57).

The master regulator of mitochondrial biogenesis, peroxisome proliferator-activated receptor $\gamma$ coactivator $1 \alpha$ (PGC-1 $\alpha$ ),

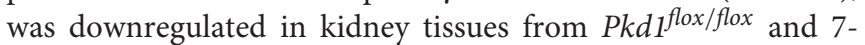
week-old $C y /+$ rats (52). PPARA and its target genes were shown to belong to a down regulated pathway in human ADPKD cysts (17). Interestingly, the mitochondria from PC2 knock-down (KD) cyst-modeling cells exhibit altered metabolic capacity and show a high degree of fragmentation, which they have in common with PKD1; however, an increased level in PCG-1 $\alpha$ was shown in PC2 KD cells (50). The reasons for these different phenotypes between cells lacking PC1 and PC2 proteins still remains unclear, but the idea that mitochondriaER communication is a common mechanism that contributes to altered metabolism in ADPKD is well-evidenced.

The major pathway for the degradation of fatty acids inside the mitochondria is mitochondrial fatty acid $\beta$-oxidation (FAO), which is the preferred energy source for highly metabolic cells and can contribute to mitochondrial dysfunction. Under physiological conditions, FAO provides more ATP than glucose oxidation (58). In $P k d 1$ knock-down cells derived from mouse cortical collecting duct (mCCD) and from immortalized proximal or distal tubule cells from $P k d 1^{c k o / c k o}$, the oxygen consumption rate (OCR) was reduced in the presence of palmitate compared to respective controls (10). The reduced FAO, observed by OCR, was shown in other cell lines derived from ADPKD mouse models $(11,12,54)$. Often, this reduction is accompanied by increased fatty acid biosynthesis, which can favor the increased de novo fatty acid synthesis (FASN) and inhibit the increased synthesis of carnitine palmitoyl transferase 1 (CPT1) transporters into the mitochondria. This was observed in $P k d 1^{-/-}$cells and kidneys from Ksp-Cre:Pkd1 flox/- when compared to controls (12). These results suggest that fatty acids derived carbons sustain reductive carboxylation for the de novo fatty acids biosynthesis through glutamine entry into the tricarboxylic acid cycle (TCA), and may also sustain the energy required for cell membranes used for proliferation. The increased in fatty acid biosynthesis was also sustained from an upregulation of key genes involved in this process derived from a subset of microarray data from human ADPKD patients (12). However, the precise mechanism of how PC1 regulates the mitochondrial metabolism is still not precisely defined and understanding the origin of these perturbations including the role of the polycystin in the regulation of the mitochondrial function needs to be defined (please refer to Figure 2 for summary of the main metabolic pathways altered in ADPKD).

\section{Glutaminolysis and Amino Acid Metabolism}

Glutamine is another important metabolite that sustains the supply of carbons and nitrogens to fuel biosynthesis of the TCA cycle metabolites (59). In standard culture, many cancer cell lines fuel the TCA cycle using acetyl-CoA produced from glucose and most of the anaeplerosis is supplied by glutamine (60). Glutamine addiction in ADPKD was first reported in the study by Hwang et al. In this study, a non-targeted metabolomics approach was investigated in autosomal recessive polycystic kidney disease (ARPKD) kidneys, and cpk (congenital polycystic kidneys) cells. The results were then validated via targeted analysis with changes in human ARPKD tissue and unaffected controls (61). Cpk cells are addicted to glutamine, which is required for the production of the oncometabolite glutamine-sourced 2-hydroxyglutarate (2HG) (61). Accumulation of 2-HG has been described in renal cell carcinoma and it is thought to contribute to enhanced proliferation through epigenetic modifications (62). This striking parallel between cancer and ADPKD was firstly evidenced in this study (61) and subsequently associated with profound metabolic reprogramming that is found in tumors. However, ADPKD does not predispose to malignancy and the reader can find further details in the following review (63).

The glutamine addiction in ADPKD opened novel therapeutic opportunities, and subsequent studies have shown that inhibition of glutaminase 1 (GLS1) via BPTES or CB-839, tested in a less aggressive model of cystic disease (Aqp2-Cre:Pkd1 $1^{f l / f l}$ and Pkhd1-Cre: Pkd1 $1^{f l f l}$ ) (64), effected proliferation and cyst growth. The inhibition of glutamine with CB-839 resulted in 

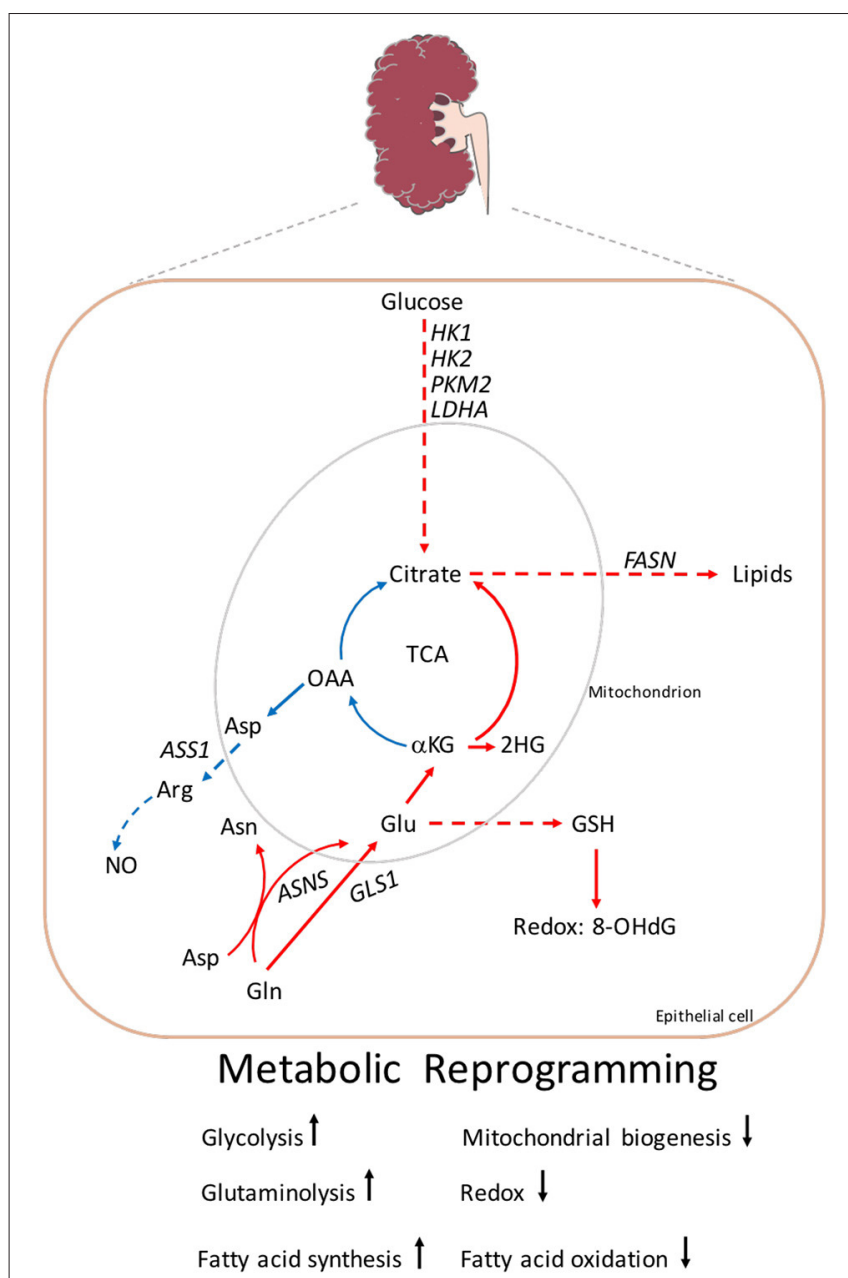

FIGURE 2 | Metabolic reprogramming in ADPKD. A screen shot of the main metabolites and key genes altered in ADPKD described in the review. Enhanced glycolysis which leads to the production of lactate. Increased glycolytic genes: HK1, HK2, PKM2, and LDHA. The TCA mitochondrial metabolites OAA and citrate are used to generate aspartate and acetyl-CoA, the latter for the production of lipids. Aspartate together with citrulline (not shown) are converted to arginine by ASS1, which synthesizes NO. The uptake of glutamine is driven by GLS, and/or through ASNS. Glutamine contributes to the generation of GSH which attenuates 8-OHdG, a product of DNA damage. Glutamine is also necessary for the production of glutamine sourced 2-HG. Gln, glutamine; Glu, glutamate; $\alpha \mathrm{KG}, \alpha$-ketoglutarate; 2-HG,

2-hydroxyglutarate; OAA, oxaloacetate; Asn, asparagine; Asp, aspartate; Arg, arginine; NO, nitric oxide; GSH, glutathione; 8-OHdG, 8-hydroxyguanosine;

FASN, fatty acid synthetase; GLS1, glutaminase 1; ASS1, arginosuccinate synthetase $1 ; H K 1$, hekoxinase1; HK2, hexokinase2; PKM2, pyruvate kinase $\mathrm{M} 2$; $L D H A$, lactate dehydrogenase. Arrow indicates metabolic reactions, while dashed lines represent pathways linking two metabolites. Color code: upregulation red, blue downregulation.

cystic amelioration in Aqp2-Cre: $P k d 1^{f l / f l}$ but not in Pkhd1-Cre: $P k d 1^{f l / f l}$ mice. The investigators identified differences in signaling pathways due to mTORC1 and ERK activation, which might explain the likely failed inhibition, suggesting the upregulation of an adaptive metabolic pathway is able to bypass GLS1 inhibition. In another study by Podrini et al., tracing studies with $\left[{ }^{13} \mathrm{C}_{5}^{15} \mathrm{~N}_{2}\right]$ glutamine revealed that $P k d 1^{-/-}$cells uptake more glutamine by utilizing the enzyme asparagine synthetase (ASNS) (12) (please refer to Figure 2). ASNS is a transamidase that converts aspartate into asparagine while deaminating glutamine to form glutamate (65). ASNS was found to be upregulated in cells lacking the $P k d 1$ gene, in cystic kidneys derived from Ksp-Cre:Pkd1 flox/-, and in a subset of microarrays from humans and murine kidneys when compared to the corresponding controls (12). To evaluate the relevance of ASNS upregulation in $\mathrm{PKD}$, silencing Asns in $P k d 1$ devoid cells completely rescued the accumulation of $\alpha$-ketoglutarate $(\alpha-K G)$, specifically reducing the contribution to glutamine-derived $\alpha-K G$ (12). One possible mechanism for the increased in ASNS is that asparagine synthesis supplies the availability of the TCA cycle intermediates and supplies the reduced nitrogen to maintain the pool of non-essential amino acid synthesis (66) but this needs to be investigated in ADPKD. In a metabolic profiling performed in children and young adults with ADPKD, Plasma samples were collected analysed with mass spectrometry (MS) and the most influential metabolite in ranked based area was asparagine, which was more than threefold higher in patients with ADPKD (67). In another study, glutamine addiction in PKD was investigated by an alternative glutamine pathway, via arginine synthetic enzyme arginosuccinate synthase1 (ASS1) directed to urea production (68). In both mouse models and human ADPKD tissue, the authors demonstrated that ASS1 expression was reduced and arginine depletion resulted in decreased cyst formation (68). Targeting arginine, via arginine-degrading enzymes, as used in clinical trials, and reviewed in Patil et al. (69), could be used to reduce circulating arginine in PKD. Collectively, these results suggest that ADPKD depends on glutamine for growth, shows increased asparagine synthetase activity, and its inhibition reduces cells growth (12).

Glutamine is also a precursor for the major antioxidant system compromised of glutathione (GSH) and oxidized glutathione (GSSG) (70). In another study by Flowers et al., the investigators found that embryonic $P k d 1 \mathrm{mCCD}$ are also dependent on glutamine, which is required for glutathione synthesis (71). The changes in glutathione metabolism and the vulnerability of mutant $P K D$ cells to reactive oxygen species (ROS) was found at a very early stage of PKD, which was reflected by increased 8-hydroxydeoxyguanosine (8$\mathrm{OHdG}$ ) that enhanced disease progression (72). The oxidative stress biomarker $8-\mathrm{OHdG}$ was increased in the kidney cystlining cells from Ksp-Cre:PKD1 flox/flox mice and $C y /+$ rats, indicating that mitochondrial abnormalities also incite oxidative stress in these cells (52). There has been a link between oxidative stress and impaired endothelial-dependent relaxation (endothelial dysfunction) in progression of kidney injury with ADPKD, as observed in Nowak et al. (73) and Klawitter et al. (74). The PC1/PC2 complex is necessary for normal vasculature development, since it is required for endothelial cilia to sense fluid shear stress through complex biochemical cascades involving many factors including nitric oxide (NO) (74). NO is produced by endothelial cells and is a critical regulator of this balance, such that endothelial dysfunction is defined as reduced capacity for NO production (75). Endothelial dysfunction and decreased endothelial NO synthetase activity 
are observed in patients (74) and young adults with ADPKD (73). Because statins have anti-inflammatory and anti-oxidant effects (76), there have been studies for the prevention of acute kidney injury after cardiac surgery (77) which predisposes to endothelial dysfunction. In a pediatric ADPKD trial, plasma levels of oxidative stress biomarkers declined during pravastatin treatment but not with placebo (78). There is also an ongoing clinical trial in adults (Pravastatin in adult phase 4, ClinicalTrials.gov Identifier: NCT03273413). However, a post hoc analysis was performed on adults in the HALT-PKD trials on statins resulting in no benefit from statin therapy (79). Whether oxidative stress is a driver of disease still needs further investigation.

\section{Mathematical Modeling of Metabolism: Application to ADPKD}

At the genome-scale level, metabolism is the result of thousands of compounds that are linked by reactions, which are continuously interacting with each other. The mathematical modeling process of metabolic networks can be broken in two steps. First, the stoichiometry of the system, which is the set of reactions representing the species connectivity, is established, and then rate laws are assigned to each reaction. For specific pathways, kinetic models based on sets of ordinary differential equations (ODEs) are broadly used to describe the metabolites' dynamic along time $(80,81)$. The foundation of this approach is the theory of molecular collisions that represents the basis of the mass action law. According to this theory, the algebraic expression for the ODEs depends on the reaction kinetics under consideration. There are several approaches for deriving kinetic functions: mass action kinetics (82), the Michaelis-Menten type and allosteric kinetics $(83,84)$, and the power-law approximation (85). The major drawback in using ODEs is the scarcity of experimental data on rate constants, especially at the genomescale level. Genome-scale metabolic models require a large number of kinetic constants, many of which have not yet been experimentally measured. Moreover, the value of these parameters are subject to high uncertainty, resulting in erroneous simulations. Stoichiometric models address these problems by assuming that the changes in the compound concentrations are the result of the topological structure of the metabolic reactions. Starting from this assumption, by applying Flux Balance Analysis (FBA), a set of ODEs is transformed into a system of linear equations, and its rates can be obtained by solving a linear programming problem that optimizes specific objective functions (86). Further constraints are added to narrow the solution space. Although these types of models do not depend on the mathematical formalization of the rate laws, their analysis can lead to general results about the reactions properties. In one study (12), a computational systems-level approach based on FBA, called Differential Flux-balance Analysis (DFA) (87, 88), was employed to gather a broader understanding of the metabolic changes observed in Pkd1 mutant cells. By employing tracing experiments with ${ }^{13} \mathrm{C}$-labeled glucose, the investigators found an 1.6 fold increase in the uptake of glucose in $\mathrm{Pkd1}^{-/-}$cells compared to controls. This data was used as mathematical constraint for DFA. The simulations suggested that an increased uptake of glucose is able to drive a statistically significant change of the bioenergetics mechanisms, such as the TCA cycle, oxidative phosphorylation, the pentose phosphate pathway, and fatty acid synthesis and oxidation. The simulations have been followed by an extensive study of the observed metabolic reprogramming by integrating in vitro and in vivo analysis with metabolomics and transcriptomics data. In a subsequent work (89), DFA has been applied to test whether these alterations are causally interconnected or if they might occur simultaneously without interfering with each other. Particularly, DFA has been integrated with a Compounds-Pathways Enrichment Analysis to simulate the metabolic changes of bioenergetics pathways observed in Podrini et al. (12): (i) increased glucose uptake; (ii) increased mitochondrial glutamine uptake; (iii) increased fatty acids synthesis; (iv) reduced fatty acids oxidation. They found that simulations of these alterations result in important overall metabolic changes in pathways that are very similar in the different conditions, suggesting that they are all interconnected by key genes and specific chemical reactions. However, slightly different alterations were observed in the different simulations and only increased glycolysis appears to be the alteration that better recapitulates simultaneously all changes observed in $P k d 1$ mutant cells, while none of the other simulations can recapitulate the overall picture, suggesting an important possible causal link and directionality of the alterations observed. In addition, DFA showed that an increased flux of citrate from mitochondria to cytosol modulates the switch toward alternative bioenergetics pathways, hence, this metabolite could be one of the key factors in the regulation of the metabolic alterations observed in ADPKD.

Computational analysis may contribute to basic research on ADPKD, but the success of this approach will certainly require new modeling and simulation tools because our current understanding of how regulations are carried out is probably still missing several significant pieces. More experimental work is needed, and these experimental results must be incorporated in improved mathematical models, which would benefit from the creation of a common modeling framework that takes into account different entities, such as genes, proteins, and metabolites, and relationships, like metabolic reactions, interactions, regulations, and transports. Several problems and requirements arise toward this strategy, such as how to deal with incomplete information, how to manipulate large models, how to extract valuable information about the regulative mechanisms, how to analyze these models, and how to infer suitable models from experimental data.

\section{SYSTEMS BIOLOGY OF ADPKD}

The goal of Systems Biology is to try to understand global dynamics and properties of biological processes on the basis of microscopic factors depending on the scale of the phenomenon under study. The unifying framework is that biological systems are the result of a high number of interacting elements that are organized, at different levels of complexity, in functional networks. Particularly, the availability of high-throughput data 
about multiple omics allows mapping cellular ADPKD processes at the level of genes, proteins, and metabolites.

The work of Song et al. (17) represents the first application of a Systems Biology approach in ADPKD. By employing microarray expression profiling from cysts of different size and from minimally cystic tissue from five PKD1 human polycystic kidneys, the authors identified that a cross-talk of specific signaling pathways modulates renal cyst expansion. They inferred downregulation of several gene sets associated with metabolic pathways like amino acids, fatty acids, urea cycle and ATP metabolism, and other kidney specific gene sets associated with ciliary functions, and renal cystic diseases. In contrast, sets of signaling genes resulted upregulated. The database developed by Song et al. still represents an invaluable resource for researchers interested in studying molecular pathobiology of ADPKD, and it was employed in several computational approaches related to ADPKD. This dataset has been analyzed in Rahimmanesh and Fatehi (90) by employing differentially expressed genes (DEGs) to construct protein-protein interactions (PPIs) networks. Enrichment analysis applied to protein clusters found in networks resulted in the detection of critical metabolic pathways such as oxidative phosphorylation and energy metabolism. The inferred networks also demonstrated that the interactions among proteins become more complex with the disease progression, while clustering revealed that EDN1, a vasoconstrictor that may promote tumor growth and for which serum levels have been associated with disease progression in ADPKD (91, 92), seems to be a seed gene in the early stage of the disorder. In addition, miRNAs and transcription factors enriched for dysregulated genes have been determined, such as hepatocyte nuclear factor alpha (HNF4A). In another study (93), the Song's database has been integrated with a mice microarrays datasets $(17,94)$, and a set of DEGs was found in both the datasets. The downregulated genes were associated with carbon metabolism, fatty acids, and amino acid metabolism. Pathways involved in cancer, PI3K-Akt signaling pathway, focal adhesion, complement, and coagulation cascades resulted enriched for the upregulated DEGs. Starting from the DEGs, the authors filtered out a PPI network containing two significant modules. One module contained proteins related to mitochondrion, degradation of valine, lysine, leucine, fatty acids, ATP binding, and metabolism of carbon, propanoate, and tryptophan. The second one was associated with protein binding, extracellular region, extracellular space, platelet degranulation, extracellular exosome, plasma membrane, and aging (93).

With the aim of revealing the gene expression signatures related to progression of ADPKD, to infer signaling pathways associated with dysregulation of gene expression, and to study the roles of miRNAs in regulating the differences between normal and cystic kidneys, Pandey et al. investigated global microarray expression profiling (95). Kidneys from $P k d 1^{-/-}$littermates at the embryonic ages 14 (E14.5) and 17 (E17.5) were investigated and even if mutants at E14.5 do not exhibit cysts, specific changes in gene expression related to signaling were observed. This result indicates that gene expression changes at E14.5 could provide an indication of signaling pathways that cause cysts rather than being a consequence of cyst formation. Most of the deregulated gene sets in $P k d 1^{-/-}$mutants compared to WT at E14.5 and
E17.5 were metabolic pathways and others involved in kidney development and regeneration. However, mutants at E17.5 days showed a broad change of genes associated with development, differentiation of specific nephron segments, and cyst formation and growth. Particularly, about 50\% of the dysregulated pathways were in common with the deregulated ones observed in human ADPKD by Song et al. (17). In order to understand if miRNAs are directly involved in cyst formation and growth, miRNA microarrays using RNA from the kidneys of control and KspCre:Kif3aflox/flox mice was performed (96). The main goal of this work was the identification of differentially expressed miRNAs. Patel and colleagues showed that the oncogenic miRNA cluster miR-17 92 is upregulated in a mouse model of PKD. This miRNA drives cyst epithelial proliferation and inhibits the posttranscriptional expression of $P k d 1, P k d 2$, and hepatocyte nuclear factor $1 \beta(H n f-1 \beta)$. An integrated analysis of miRNA and RNAsequencing was employed in (94) to investigate the miRNA profiles correlated with the severity of cyst development in two ADPKD models, kidney-specific $P k d 1$ or $P k d 2 \mathrm{KO}$ mice, at three time points, P1, P3, and P7. Woo et al. discovered differentially expressed miRNAs that were common in both mouse models. Particularly, a small subset of these miRNAs have been associated with cytogenesis-related pathways. The role of miRNAs in ADPKD has also been recently studied in (97) by employing a transcriptional profiling of orthologous mouse models and cystic kidneys from humans with ADPKD. Lakhia et al. (97) showed that miRNAs represent molecular signals in the crosstalk between cyst microenvironment and immune cells. Particularly, miR-214 is upregulated in both mice and human PKD, while miR-214 deletion worsened cyst enlargement in the $P k d 2 \mathrm{KO}$ murine model of ADPKD and increased cyst-related inflammation. This result suggests that miR-214 is a protective signal against cyst development and formation.

Since it has been observed that the kinetics of cyst formation after $P k d 1$ inactivation in mice is sensitive to the age, specifically between days 12 and 14 (98), a network analysis has been applied to transcriptomics data from 36 mutants and 34 controls kidneys in order to study the changes during the P12-P14 interval that have such a drastic modifier effect in ADPKD (99). They inferred a cluster of DEGs enriched for several gene ontology categories related to metabolic pathways, development, cell differentiation, and anatomical structure morphogenesis. A gene ontology analysis suggested that metabolic pathways represent a key element in post-natal kidney development and the first step of cyst formation. The alteration of metabolic pathways has been confirmed by a metabolomics analysis of urine from 84 mice, which also showed an impairment of tyrosine metabolism, oxidative phosphorylation, purine metabolism, and aminoacyl-tRNA biosynthesis.

Finally, we would like to point out that long non-coding RNAs (lncRNAs) have emerged as epigenetic regulators of disorders and development. However, their role in ADPKD is not very clear yet. Therefore, RNA-sequencing analysis has been performed (100) with the aim to identify lncRNAs dysregulated in ADPKD. Several lncRNAs were deregulated in two kidneys specific $P k d 1$ and $P k d 2$ mutant mice. One of these, Hoxb3os, regulates a network of genes and signaling pathways that are commonly 
dysregulated in ADPKD. The ortholog HOXB3-AS1 has been found to be downregulated in cystic kidneys from ADPKD patients. Several genes were differentially expressed between Hoxb3os KO and control cells. Pathway analysis suggested that Hoxb3os regulates mTOR pathway and metabolism in mouse kidney ADPKD cells. Specifically, Hoxb3os could represent a negative regulator of mTORC1 activity and mitochondrial respiration, suggesting that re-expression of Hoxb3os could be used as a therapeutic strategy in ADPKD.

In conclusion, it is important to highlight that the Systems Biology tools developed in the last few years represent powerful methods to generate systematic views of the ADPKD, with the aim of exploring the comprehensive molecular mechanisms of this disease.

\section{Emerging Therapeutics and Systems Medicine in ADPKD}

The pathophysiology behind ADPKD is not completely understood, but a "threshold model" of cytogenesis is supported by previous studies (101-103). In this model, reduction of cellular levels of PC1 can influence cystic disease severity by a complexity of signaling pathways (104). However, re-establishing the levels of PC1 to restore normal cystic tissue remains an elusive approach. Targeting altered signaling pathways that drive cytogenesis (104) may be the preferred strategic approach to ameliorate disease progression in ADPKD. As a consequence of vasopressin V2receptor activation, dyregulated signaling pathways in ADPKD such as increased cyclic adenosine monophosphate (cAMP) concentration, resulted in the identification of tolvaptan as a first treatment for $\operatorname{ADPKD}(105,106)$. The activity of key energy metabolic enzymes was shown to be central in the metabolic shift of ADPKD. For example, AMP-activated protein kinase (AMPK) decreased $(9,107)$, while mTORC1 and ERK increased $(108,109)$. It was proposed that the decreased phosphorylation of AMPK is due to regulation of the liver kinase B1 (LKB1)/AMPK axis $(9,16)$. In another study, it was reported that the activation of the mitogen-activated protein kinase (MAPK)-ERK pathway was observed in an acute perinatal PKD model; however, an inhibitor against ERK was not able to prevent cyst formation and may not be the basis for cyst expansion (110). Inhibitors of the mTORC1 complex, including sirolimus and everolimus, have been tested in five clinical trials. The results of the clinical trials showed no beneficial effects on the rate of change of total kidney volume (TKV) (111).

A novel therapeutic approach that targets mRNA expression is to utilize the action of an antisense oligonucleotide (ASO), a single-stranded deoxyribonucleotide that is complimentary to the mRNA target. The goal of the ASO is the down regulation of a specific molecular target (112-114). Therapeutic use of ASOs has been approved by the FDA for various pathologies (115). An ASO target strategy has been tested by chronic administration of mTORC1 ASO in $P k d 2^{W 25 /-}$ mice, a homologous model of human PKD caused by a mutation in the $P k d 2$ gene, and resulted in improvement of the renal cystic phenotype (116). ADPKD also effects endothelial dysfunction (117) and circulating bioactive lipid mediators (118) which can contribute to metabolic disorders. From a clinical point of view, there is a higher incidence of new onset of diabetes mellitus after transplantation in recipients with ADPKD vs. other primary kidney diseases (119). To tackle a broad range of metabolic disorders in relation to vascular damage in ADPKD, clinical trials have been conducted with angiotensin-converting enzyme (ACE) inhibitors in ADPKD patients $(31,67)$. These trials have not been successful in decreasing renal function (120). Alternatively, the use of ASO against angiotensin (AGT) has been investigated in pre-clinical studies $(116,121,122)$. The ASOs resulted in an improved cystic phenotype in the $P k d 2^{W S 25}$ model (123) and in the global (121) and in the tamoxifen-inducible knockout model of PKD (122). This suggests that targeting AGT with ASO may be more efficient than ACE inhibitors, and could open novel therapeutic opportunities for targeting abnormal signaling cyst formation in ADPKD.

The inhibition of mitochondrial function by anti-miR $\sim 17-$ 92 attenuates disease progression in ADPKD mouse models irrespective of the mutated gene ( $P k d 1$ or $P k d 2)$, the type of mutation (null or hypomorphic) or the dynamics of cyst growth (54). An anti-miR-17 oligonucleotide has proved to be efficient in reducing cyst formation in PKD mouse models $(54,124)$. Based on these results, anti-miR-17 oligonucleotides were designed and screened with favorable pharmaceutical properties (125). In fact, a phase 1 trial with an anti-miR-17 drug (RGLS4326) is currently being performed in ADPKD patients (ClinicalTrials.gov Identifier: NCT04536688). The miR-17 family is a promising drug target for ADPKD. Recent evidence shows that large clusters of transcriptional enhancers, super-enhancers (SE), undergo extensive remodeling during cytogenesis and that SE-associated transcripts are most enriched for metabolic genes in cystic cells (126). AMP deaminase 3 (AMPD3), a key enzyme involved in AMP metabolism and AMPK activation, was found to be SE-driven in cyst development. Inhibiting AMPD3 by pentostatin, or cyclic dependent kinase 7 (CDK7), one of the controlled metabolic target genes, decreased cell proliferation and apoptosis in ADPKD cells and delayed disease progression in tamoxifen-inducible $P k d 1$ mice with slowly progressing ADPKD (126). These findings suggest that CDK7- containing SEs are critical in ADPKD. As for therapy, inhibiting AMPD3, could be beneficial to target before disease progression and can provide a greater efficacy than targeting the downstream effectors in ADPKD (please refer to Figure 3 for an overview of therapeutical targets).

Recent preclinical data have generated promising results for targeting cellular bio-energetics in ADPKD. The high rate of glycolysis encountered in ADPKD has been targeted with glucose analog 2-DG in orthologous mouse models of ADPKD $(9,107,127)$ with effective cystic amelioration. A phase 1 clinical trial has been designed with 2-DG in an ADPKD cohort (128). In addition, the dependence on glucose in cystic cells opened new venues to target disease by modifying diet for cystic amelioration. In fact, 2-DG can be compared to calorie restriction without reducing food intake given its capability to reduce metabolic rate addiction to glucose (129). Thus, ketogenic diets that decrease glucose availability have been tested in ADPKD, with the hypothesis that ketogenesis may 


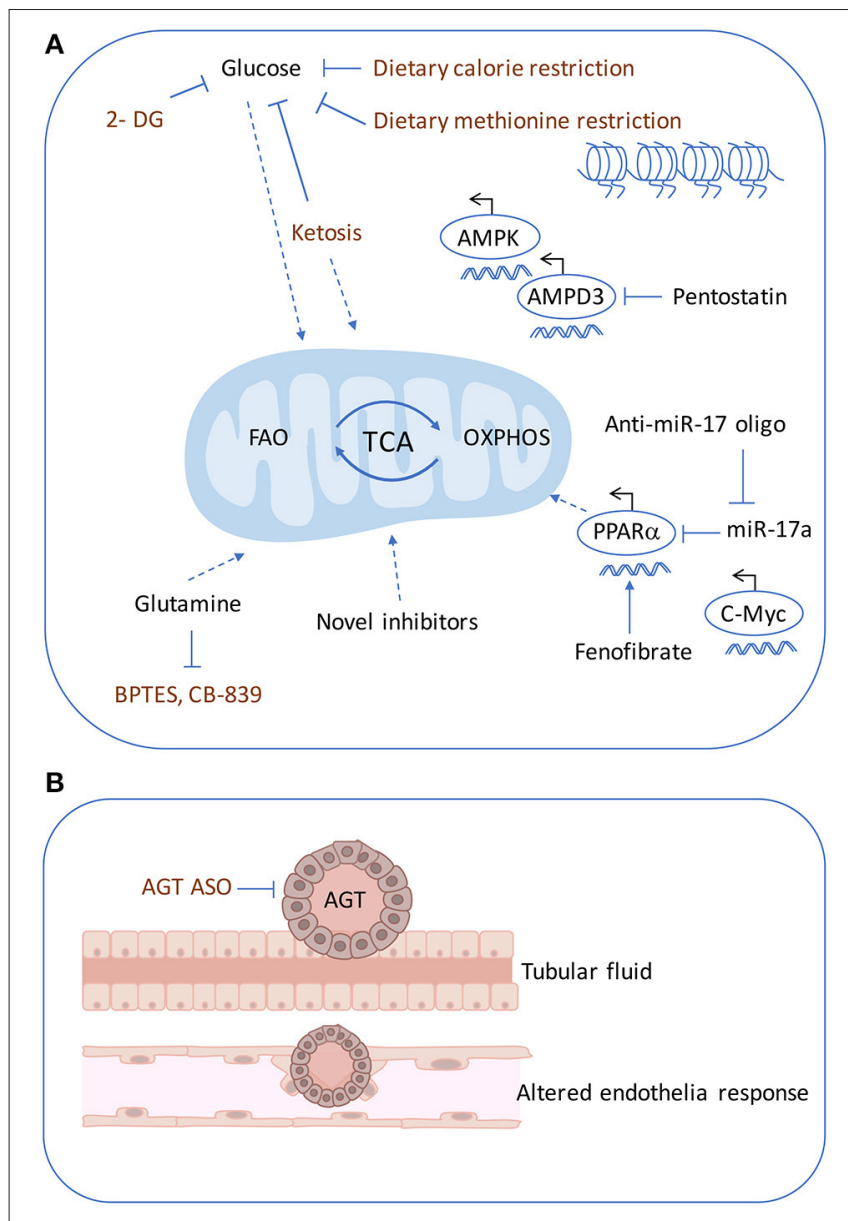

FIGURE 3 | Therapeutics targets in ADPKD. Multiple pharmacological approaches are known to ameliorate cyst formation in ADPKD. (A) Glycolysis can be targeting using 2-DG and similarly with dietary restrictions such as, ketogenic diet, methionine restriction. The dietary restrictions also affect mitochondrial metabolism. OXPHOS defects can be rescued by using an anti-miR-17 oligonucleotide, PPAR $\alpha$ inhibitor or fenofibrate PPAR $\gamma$ agonist. Super-enhancers driven cyst formation through AMPD3 can be inhibited by pentostatin. (B) Cyst expansion may compress the arterioles and trigger increased AGT causing altered endothelial response. ASO against, AGT, was shown to inhibit cyst formation. 2-DG, 2-deoxyglucose; AGT, angiotensin; ASO, antisense oligonucleotide.

be beneficial in preventing cyst formation. This hypothesis was evaluated in an ADPKD rat model and in a spontaneous feline model of ADPKD, where a high ketogenic diet resulted in strong inhibition of PKD progression (39). The increase in ketosis was also investigated by acute fasting in mouse, rat, and feline models of PKD and significantly reduced renal cystic burden in all three models (39). Currently, there is an on-going clinical trial on the short term induction of ketosis in ADPKD patients (ClinicalTrials.gov Identifier: NCT04472624) and also the patent-pending supplements are also being formulated and will be tested in the near future in clinical trials (130). Furthermore, prior to testing the ketogenic diet calorie restriction was found to reduce cyst growth (131, 132). There is growing evidence that diet manipulation can be a modifier of ADPKD disease and that the plethora of metabolic dysregulation observed in ADPKD may support the proliferating cyst epithelia. One possible mechanism is through the impact of one-carbon and methionine metabolism which generate the essential methyl groups for which altered nutrient utilization is facilitated. Ramalingam et al. found a higher methionineS-adenosyl methionine (SAM) levels and methyltransferaselike 3 (Mettl3) upregulation in multiple ADPKD mouse models and that methionine-SAM supplementation or Mettl3 overexpression induced cyst growth (133). Dietary methionine restriction or Mettl3 ablation attenuated $\mathrm{PKD}$, which may be regulated through epitranscriptomic mechanism through c-Myc and cAMP signaling activation (133). As for therapy, a veganbased diet could also be used to ameliorate cyst formation, as methionine is found in meat and fish; alternatively, METTL3 inhibitors may also be targetable for ADPKD but warrants further investigation.

Tolvaptan, as already mentioned, is the unique drug that has been approved, in several countries, for the treatment of ADPKD (134). Frequent liver chemistry monitoring is suggested for patients using Tolvaptan, as it caused liver enzyme elevations in two pivotal Phase III clinical trials in ADPKD patients (42, 106). Taking into account this information, there is an urgent need for new compounds that can be used to stop the disorder progression.

A novel approach for identifying new drugs for ADPKD has been investigated by Malas et al. (14). Their approach combines integrated computational tools, repurposing analysis, cheminformatics data, and RNA sequencing of $P k d 1 \mathrm{KO}$ mice at different disease stages in order to identify new drugs for ADPKD. Results from this approach indicated that three compounds (i.e., Meclofenamic acid, Gamolenic acid, and Birinapant) are able to inhibit cyst swelling in vitro without toxicity, and could be further investigated for the treatment of ADPKD. Meclofenamic acid targets the aldo-keto reductase family 1 , which is involved in steroid metabolism (135), a pathway known to be a player in cyst development in a PKD rat model (136). Gamolenic acid has been selected based on PPAR $\delta$, a nuclear hormone receptor that controls a set of metabolic genes belonging to glucose metabolism, and fatty acid synthesis, storage, mobilization, and catabolism. Members of the PPAR family have been studied in preclinical trials for $\operatorname{PKD}(55,137)$. Birinapant represents a second mitochondrial-derived activator of caspases (SMAC) mimetic that modulates apoptosis (138). It has been found that the SMAC mimetic GT13072 reduces PKD progression in a $P k d 1$ mouse model (139).

Lixivaptan, another vasopressin $\mathrm{V}_{2}$ receptor antagonist, was proposed for ADPKD treatment. This compound was initially developed for treating hyponetremia (140), and it has been evaluated by applying quantitative systems toxicology modeling (141). Their results showed that when compared to Tolvaptan, Lixivaptan had a significantly lower risk of hepatotoxicity at their respective doses for ADPKD treatment; therefore, it is a good candidate for continued study in the treatment of this disorder. The difference in the toxicity mechanisms between Tolvaptan and Lixivaptan demonstrates 
the fact that even compounds within the same class can vary widely in terms of potential liability and potential mechanisms of toxicity.

Based on drug repositioning, Asawa et al. developed a highthroughput screening platform for ADPKD (13) that employs $P k d 1$-null postnatal cells of proximal tubule origin, $P k d 1$-null mouse embryonic kidney cells of collecting duct origin (MEKnull), and $P k d 1^{-/-}$human kidney epithelial cells in order to evaluate a set of 8814 approved drugs and studied compounds principally having anti-neoplastic usage. It resulted in 155 compounds that reduced the viability of mutant cells but had minimal effects on wild-type cells. The investigators inferred that 109 of these compounds reduced cyst growth in $P k d 1^{-/-}$ cells cultured in a 3D matrix. Furthermore, with the aim of screening out possible therapies that failed to be translated in the treatment of the human disease, the platform has been extended by introducing the evaluation of the compounds in a panel of primary ADPKD and control human kidney epithelial cells. This step allowed the repurposing of 18 compounds that affected the viability of ADPKD cells with minimal effects on control human kidney epithelial cells. These compounds are: (i) Briciclib, Prexasertib, AHPN, and IMD-0354 which have been not yet been analyzed in the context of ADPKD; (ii) Cytarabine, Ancitabine, Clofarabine, Gemcitabine, Adefovir, and Topotecan, Belotecan, and 9-Methoxycamptothecin, which inhibit the proliferation of $\mathrm{Pkd1}^{-/-}$cells by directly interfering with DNA replication; (iii) Combretastatin A-4, Leptomycin B, Delanzomib, CB30865, Cerivastatin, and Pitavastatin which have been previously proposed as potential therapeutic options for ADPKD (142-144).

In short, given the complexity of the altered pathways in cyst-lining epithelia, and the availability of a broad range of potential targets, powerful strategies are needed to make faster advances in this field. Systems medicine and drug repurposing for the development of new treatments can help expedite the discovery of new effective treatments. The tools and the approaches presented in this section represent valuable platforms to repurpose chemical compounds and to identify drug targets for ADPKD treatment. All the presented studies discussed are of high relevance to ADPKD patients, as Tolvaptan, is the only approved therapy but has limited treatment options. The identified compounds represent a starting point for future efficacy studies employing relevant ex vivo and in vivo ADPKD models.

\section{USE OF OMICS DATA AND FUTURE THERAPEUTICS IN ADPKD}

Omics data are valuable tools for elucidating key genes and pathways associated with different aspects of ADPKD. However, one of the main drawbacks is the much of the profiling data from mouse models and patients has been published on public databases (the reader can find details about the most known datasets in Table 2), but it has not yet been exhaustively analyzed with the most appropriate computational approaches. Some points have to be carefully considered: (i) how samples are organized in different groups in order to follow a differential expression analysis; (ii) how results from a computational analysis are corrected for multiple comparisons in order to have strong statistics; and (iii) how to take into consideration that data from independent studies could be limited by the fact that they were derived from single cohort and by the samples heterogeneity.

It has also been observed that genome-scale profiling analysis can lack reproducibility because a large number of hypothesis tests are based on relatively small sample sizes. This problem can be solved by executing a meta-analysis based on the integration of different studies, which can increase statistical power and lead to more robust inferences $(162,163)$. However, the development of reliable tools to integrate different datasets remains a challenge due to low data comparability and consistency. A cross species meta-analysis was carried out by (164) with the aim of identifying conserved pathways that could be key targets for ADPKD therapy. Their analysis was rooted on mouse, rat, and human microarray datasets and revealed statistically significant enriched dysregulated pathways and processes conserved across all the species. Processes related to genomic instability, growth factors and hormones, protein localization in ER and insulin resistance promote cysts formation that is regulated by key pathways mediating apoptosis, cell proliferation, cell adhesion, and differentiation. In contrast, cysts progression seems to be a consequence of processes associated with cell adhesion and inflammation. In addition, a causative link among immune response pathways, signaling pathways, and cellular architecture pathways seems to affect cyst development.

Regarding the drug repositioning for the ADPKD, we would like to highlight that treatments and their targets are biased toward the most studied proteins and disorders. Future functional wet-experiments are needed to infer the actual contribution of each gene involved in cyst enlargement and disease progression. Further investigations will be facilitated by the development and the continuous update of the molecules database with drug-like properties.

Of note, there is a lack of knowledge about specific biomarkers, particularly in ADPKD pediatric patients. A recent work tried to identify plasma fingerprints in children and young adult patients with preserved kidney functions (67). The goal of the study was to identify markers and associated pathways involved in the progression of pediatric ADPKD over 36 months. The authors collected plasma samples from 58 young patients during a phase III clinical trial designed to test the effectiveness of pravastatin on slowing down cyst progression. In this study, metabolomics analysis revealed that metabolites deriving from the TCA cycle were associated with ADPKD progression. This is a set example of how metabolomics can offer a powerful tool for the prediction of the patient outcomes in clinical trials. However, there are also limited therapies focusing on treating ADPKD in early childhood where the benefits could be more likely. Screening of at-risk children is controversial and not recommended $(1,165)$ because of its potential to cause psychological harm. There is not yet a means of stratifying patients by rapid progressors of disease or not. To achieve this, it will be fundamental to start lifelong therapy at a later stage. The 
TABLE 2 | A list of datasets related to ADPKD.

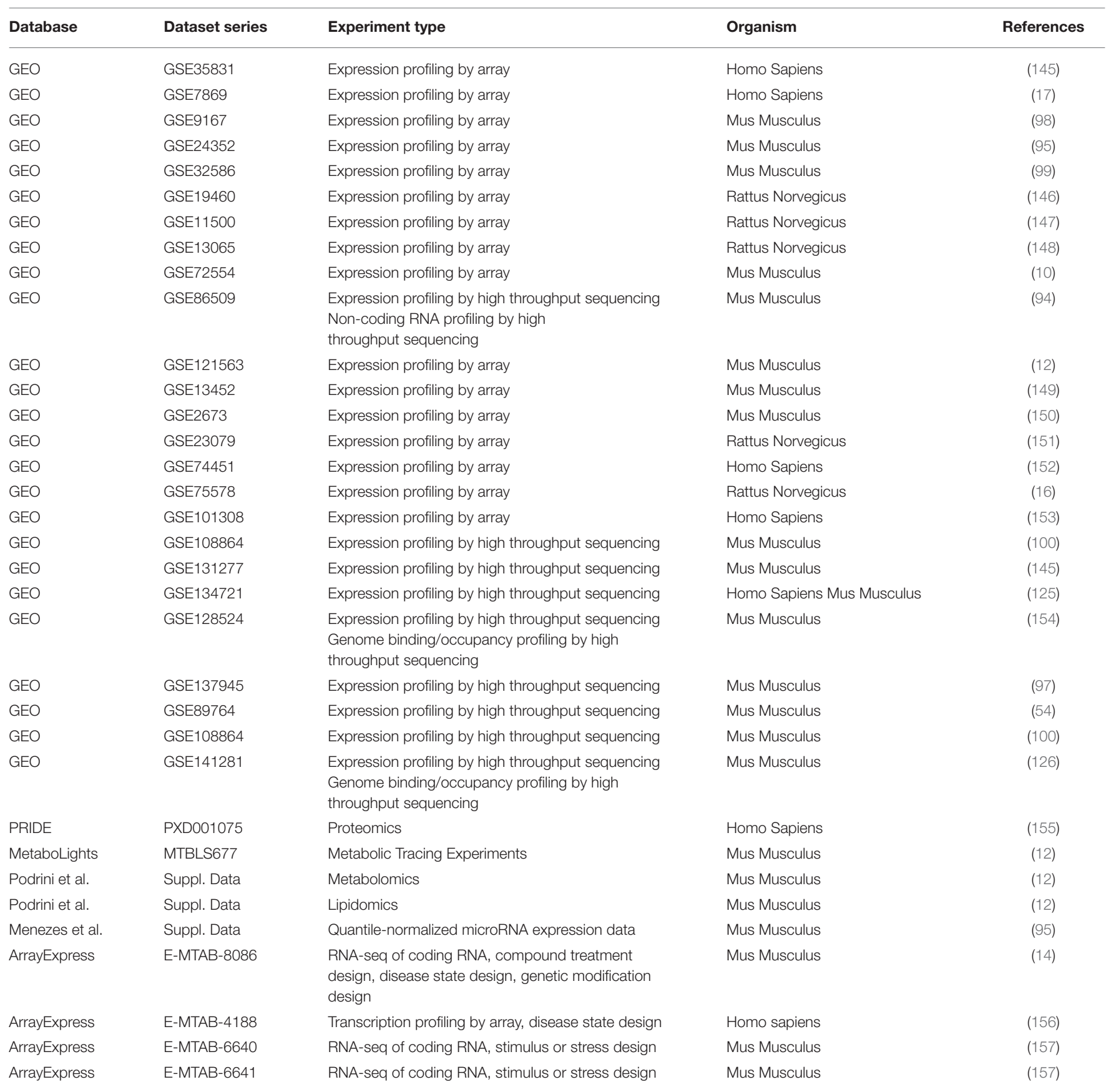

Details about the different databases can be found in the following papers: GEO (158), MetaboLights (159), ArrayExpress (160), and Pride (161).

main burden of ADPKD is that it does not occur until adulthood and some children are usually asymptomatic. This may, as a consequence, influence their life-style. There is a significant discrepancy regarding data obtained in adults vs. children as diagnostic criteria are highly variable, leading to incomparable studies and results (166). In children with ADPKD, EU guidelines recommends to stratify high risk patients and Tolvaptan is currently being tested in EU in children with ADPKD with high risk of rapid progression (167). The result of this study could form the basis for understanding the tolerability of tolvaptan in patients who still have a good renal function and not yet compromised. What remains to be evaluated is whether the treatment could be effective if initiated at an early stage, before cysts are formed, while the kidneys are still well-preserved.

Several effective therapies are under current investigation. It is unclear why defective PKD proteins alter signaling pathways involved in bio-energetics processes. Despite the gap of knowledge, current therapeutic interventions and clinical trials are ongoing with promising results. It is still debated whether the best strategy is to target one single pathway or to target 
multiple pathways simultaneously. In the future, an increase in the application of less invasive therapies, such as dietary restrictions, may be proposed to patients because, as described above, certain dietary interventions have been successful in slowing the progression of ADPKD in animal models. For example, time-restricted feeding improved kidney function and reduced cytogenesis, and a ketogenic diet also demonstrated similar beneficial effects in ameliorating cytogenesis (39). Human trials are ongoing and this will be a stepping stone to pursue non-invasive therapies which can be exploited and refined with a customized diet. Although the results seem promising, the benefits of the PKD ketogenic diet in human are unpredictable and the risk of potential side effects, such as cardiovascular problems or impaired liver function, is unknown. It is known that nutritional aspects such as high fluid and low sodium diet are beneficial for improving cysts formation and are also able to restrict phosphorus and protein intake (168); however, this intervention is not prescribed in the presence of a severe renal function. At present, perhaps the important aspect to consider would be to follow a balanced diet and to avoid a large amount

\section{REFERENCES}

1. Chapman AB, Devuyst O, Eckardt KU, Gansevoort RT, Harris $\mathrm{T}$, Horie $\mathrm{S}$, et al. Autosomal-dominant polycystic kidney disease (ADPKD): executive summary from a Kidney Disease: Improving Global Outcomes (KDIGO) Controversies Conference Kidney Int. (2015) 88:17-27. doi: 10.1038/ki.2015.59

2. Porath B, Gainullin VG, Cornec-Le Gall E, Dillinger EK, Heyer CM, Hopp $\mathrm{K}$, et al. Mutations in GANAB, Encoding the Glucosidase IIalpha Subunit, Cause Autosomal-Dominant Polycystic Kidney and Liver Disease. Am J Hum Genet. (2016) 98:1193-207. doi: 10.1016/j.ajhg.2016.05.004

3. Sandford R, Sgotto B, Aparicio S, Brenner S, Vaudin M, Wilson RK, et al. Comparative analysis of the polycystic kidney disease 1 (PKD1) gene reveals an integral membrane glycoprotein with multiple evolutionary conserved domains. Hum Mol Genet. (1997) 6:1483-9. doi: 10.1093/hmg/6.9.1483

4. Su Q, Hu F, Ge X, Lei J, Yu S, Wang T, et al. Structure of the human PKD1PKD2 complex. Science. (2018) 361:eaat9819. doi: 10.1126./science.aat9819

5. Qian F, Germino FJ, Cai Y, Zhang X, Somlo S, Germino GG. PKD1 interacts with PKD2 through a probable coiled-coil domain. Nat Genet. (1997) 16:179-83. doi: 10.1038/ng0697-179

6. Nauli SM, Alenghat FJ, Luo Y, Williams E, Vassilev P, Elia L, et al. Polycystins 1 and 2 mediate mechanosensation in the primary cilium of kidney cells. Nat Genet. (2003) 33:129-37. doi: 10.1038/ng1076

7. Delling M, Indzhykulian AA, Liu X, Li Y, Xie T, Corey DP, et al. Primary cilia are not calcium-responsive mechanosensors. Nature. (2016) 531:65660. doi: 10.1038/nature17426

8. Bergmann C, Guay-Woodford LM, Harris PC, Horie S, Peters DJM, Torres VE. Polycystic kidney disease. Nat Rev Dis Primers. (2018) 4:50. doi: 10.1038/s41572-018-0047-y

9. Rowe I, Chiaravalli M, Mannella V, Ulisse V, Quilici G, Pema M, et al. Defective glucose metabolism in polycystic kidney disease identifies a new therapeutic strategy. Nat Med. (2013) 19:488-93. doi: 10.1038/nm.3092

10. Menezes LF, Lin CC, Zhou F, Germino GG. Fatty acid oxidation is impaired in an orthologous mouse model of autosomal dominant polycystic kidney disease. Ebiomedicine. (2016) 5:183-192. doi: 10.1016/j.ebiom.2016. 01.027

11. Padovano V, Kuo IY, Stavola LK, Aerni HR, Flaherty BJ, Chapin HC, et al. The polycystins are modulated by cellular oxygen-sensing pathways and regulate mitochondrial function. Mol Biol Cell. (2017) 28:2619. doi: 10.1091/mbc.e16-08-0597 of refined carbohydrates. Further impact studies are needed on this issue as to address the benefits of non-invasive therapies in $\mathrm{ADPKD}$

\section{AUTHOR CONTRIBUTIONS}

$\mathrm{CP}$ and RP wrote the manuscript, reviewed and edited the manuscript before submission. Both authors contributed to the article and approved the submitted version.

\section{FUNDING}

The work on metabolism and PKD was funded by the Italian Ministry of Health (GR-2016-02364851 to $\mathrm{CP}$ and $\mathrm{RP})$.

\section{ACKNOWLEDGMENTS}

The authors are grateful to other members of the laboratory of Dr. A. Boletta for helpful suggestions.

12. Podrini C, Rowe I, Pagliarini R, Costa ASH, Chiaravalli M, Meo D, et al. Dissection of metabolic reprogramming in polycystic kidney disease reveals coordinated rewiring of bioenergetic pathways. Commun Biol. (2018) 1:194. doi: 10.1038/s42003-018-0200-x

13. Asawa RR, Danchik C, Zahkarov A, Chen Y, Voss T, Jadhav A, et al. A high-throughput screening platform for Polycystic Kidney Disease (PKD) drug repurposing utilizing murine and human ADPKD cells. Sci Rep. (2020) 10:4203. doi: 10.1038/s41598-020-61082-3

14. Malas TB, Leonhard WN, Bange H, Granchi Z, Hettne KM, Van Westen GJP, et al. Prioritization of novel ADPKD drug candidates from disease-stage specific gene expression profiles. EBioMed. (2020) 51:102585. doi: 10.1016/j.ebiom.2019.11.046

15. Chen L, Zhou X, Fan LX, Yao Y, Swenson-Fields KI, Gadjeva M, et al. Macrophage migration inhibitory factor promotes cyst growth in polycystic kidney disease. J Clin Invest. (2015) 125:2399-412. doi: 10.1172/JCI80467

16. Riwanto M, Kapoor S, Rodriguez D, Edenhofer I, Segerer S, Wuthrich RP. Inhibition of aerobic glycolysis attenuates disease progression in polycystic kidney disease. PLoS ONE. (2016) 11:e0146654. doi: 10.1371/journal.pone.0146654

17. Song X, Giovanni Di V, He N, Wang K, Ingram A, Rosenblum ND, et al. Systems biology of autosomal dominant polycystic kidney disease (ADPKD): computational identification of gene expression pathways and integrated regulatory networks. Hum Mol Genet. (2009) 18:232843. doi: $10.1093 / \mathrm{hmg} / \mathrm{ddp} 165$

18. Hallows KR, Althouse AD, Li B, Saitta B, Abebe KZ, Bae KT, et al. Association of baseline urinary metabolic biomarkers with ADPKD severity in TAME-PKD clinical trial participants. Kidney. (2021) 2:795808. doi: 10.34067/KID.0005962020

19. Seliger SL, Abebe KZ, Hallows KR, Miskulin DC, Perrone RD, Watnick $\mathrm{T}$, et al. A randomized clinical trial of metformin to treat autosomal dominant polycystic kidney disease. Am J Nephrol. (2018) 47:35260. doi: 10.1159/000488807

20. Schrier RW. Optimal care of autosomal dominant polycystic kidney disease patients. Nephrology. (2006) 11:12430. doi: 10.1111/j.1440-1797.2006.00535.x

21. Shamshirsaz AA, Reza Bekheirnia M, Kamgar M, Johnson AM, McFann K, Cadnapaphornchai $M$, et al. Autosomal-dominant polycystic kidney disease in infancy and childhood: progression and outcome. Kidney Int. (2005) 68:2218-24. doi: 10.1111/j.1523-1755.2005. 00678.x 
22. Taylor M, Johnson AM, Tison M, Fain P, Schrier RW. Earlier diagnosis of autosomal dominant polycystic kidney disease: importance of family history and implications for cardiovascular and renal complications. Am J Kidney Dis. (2005) 46:415-23. doi: 10.1053/j.ajkd.2005.05.029

23. Cadnapaphornchai MA, Fick-Brosnahan GM, Duley I, Johnson AM, Strain JD, DeGroff CG, et al. Design and baseline characteristics of participants in the study of antihypertensive therapy in children and adolescents with autosomal dominant polycystic kidney disease (ADPKD). Contemp Clin Trials. (2005) 26:211-22. doi: 10.1016/j.cct.2005.01.001

24. Fick-Brosnahan GM, Belz MM, McFann KK, Johnson AM, Schrier RW. Relationship between renal volume growth and renal function in autosomal dominant polycystic kidney disease: a longitudinal study. Am J Kidney Dis. (2002) 39:1127-34. doi: 10.1053/ajkd.2002.33379

25. Kelleher CL, McFann KK, Johnson AM, Schrier RW. Characteristics of hypertension in young adults with autosomal dominant polycystic kidney disease compared with the general U.S. population. Am J Hypertens. (2004) 17:1029-34. doi: 10.1016/j.amjhyper.2004.06.020

26. Cadnapaphornchai MA, George DM, McFann K, Wang W, Gitomer B, Strain JD, et al. Effect of pravastatin on total kidney volume, left ventricular mass index, and microalbuminuria in pediatric autosomal dominant polycystic kidney disease. Clin J Am Soc Nephrol. (2014) 9:88996. doi: 10.2215/CJN.08350813

27. Kim K, Trott JF, Gao G, Chapman A, and Weiss RH. Plasma metabolites and lipids associate with kidney function and kidney volume in hypertensive ADPKD patients early in the disease course. BMC Nephrol. (2019) 20:66. doi: 10.1186/s12882-019-1249-6

28. Schrier RW, Abebe KZ, Perrone RD, Torres VE, Braun WE, Steinman TI, et al. Blood pressure in early autosomal dominant polycystic kidney disease. N Engl J Med. (2014) 371:2255-66. doi: 10.1056/NEJMoa1402685

29. Hogan MC, Abebe K, Torres VE, Chapman AB, Bae KT, Tao C, et al. Liver involvement in early autosomal-dominant polycystic kidney disease. Clin Gastroenterol Hepatol. (2015) 13:155-64. e6. doi: 10.1016/j.cgh.2014.07.051

30. Torres VE, Chapman AB, Perrone RD, Bae KT, Abebe KZ, Bost JE, et al. Analysis of baseline parameters in the HALT polycystic kidney disease trials. Kidney Int. (2012) 81:577-85. doi: 10.1038/ki.2011.411

31. Torres VE, Abebe KZ, Chapman AB, Schrier RW, Braun WE, Steinman TI, et al. Angiotensin blockade in late autosomal dominant polycystic kidney disease. N Engl J Med. (2014) 371:2267-76. doi: 10.1056/NEJMoa1402686

32. Ruggenenti P, Gentile G, Perico N, Perna A, Barcella L, Trillini M, et al. Effect of sirolimus on disease progression in patients with autosomal dominant polycystic kidney disease and CKD stages 3b-4. Clin J Am Soc Nephrol. (2016) 11:785-94. doi: 10.2215/CJN.09900915

33. Wahl PR, Serra AL, Le Hir M, Molle KD, Hall MN, Wuthrich RP. Inhibition of mTOR with sirolimus slows disease progression in Han:SPRD rats with autosomal dominant polycystic kidney disease (ADPKD). Nephrol Dial Transplant. (2006) 21:598-604. doi: 10.1093/ndt/gfil81

34. Serra AL, Poster D, Kistler AD, Krauer F, Raina S, Young J, et al. Sirolimus and kidney growth in autosomal dominant polycystic kidney disease. N Engl J Med. (2010) 363:820-9. doi: 10.1056/NEJMoa0907419

35. Braun M, Young J, Reiner CS, Poster D, Wuthrich RP, and Serra AL. Ovarian toxicity from sirolimus. N Engl J Med. (2012) 366:10624. doi: 10.1056/NEJMc1113145

36. Braun M, Young J, Reiner CS, Poster D, Krauer F, Kistler AD, et al. Low-dose oral sirolimus and the risk of menstrual-cycle disturbances and ovarian cysts: analysis of the randomized controlled SUISSE ADPKD trial. PLoS ONE. (2012) 7:e45868. doi: 10.1371/journal.pone.0045868

37. Serra AL, Kistler AD, Poster D, Struker M, Wuthrich RP, Weishaupt D, et al. Clinical proof-of-concept trial to assess the therapeutic effect of sirolimus in patients with autosomal dominant polycystic kidney disease: SUISSE ADPKD study. BMC Nephrol. (2007) 8:13. doi: 10.1186/1471-2369-8-13

38. Walz G, Budde K, Mannaa M, Nurnberger J, Wanner C, Sommerer $\mathrm{C}$, et al. Everolimus in patients with autosomal dominant polycystic kidney disease. N Engl J Med. (2010) 363:830-40. doi: 10.1056/NEJMoa10 03491

39. Torres JA, Kruger SL, Broderick C, Amarlkhagva T, Agrawal S, Dodam $\mathrm{JR}$, et al. Ketosis ameliorates renal cyst growth in polycystic kidney disease. Cell Metab. (2019) 30:1007-23.e5. doi: 10.1016/j.cmet.2019. 09.012
40. Gattone VH II, Wang X, Harris PC, Torres VE. Inhibition of renal cystic disease development and progression by a vasopressin V2 receptor antagonist. Nat Med. (2003) 9:1323-6. doi: 10.1038/nm935

41. Torres VE, Wang X, Qian Q, Somlo S, Harris PC, Gattone VH II. Effective treatment of an orthologous model of autosomal dominant polycystic kidney disease. Nat Med. (2004) 10:363-4. doi: 10.1038/nm1004

42. Watkins PB, Lewis JH, Kaplowitz N, Alpers DH, Blais JD, Smotzer DM, et al. Clinical pattern of tolvaptan-associated liver injury in subjects with autosomal dominant polycystic kidney disease: analysis of clinical trials database. Drug Saf. (2015) 38:1103-13. doi: 10.1007/s40264-015-0327-3

43. Torres VE, Gansevoort RT, Czerwiec FS. Tolvaptan in autosomal dominant polycystic kidney disease. N Engl J Med. (2013) 368:1259. doi: 10.1056/NEJMc1300762

44. Torres VE, Meijer E, Bae KT, Chapman AB, Devuyst O, Gansevoort RT, et al. Rationale and design of the TEMPO (Tolvaptan Efficacy and Safety in Management of Autosomal Dominant Polycystic Kidney Disease and its Outcomes) 3-4 Study. Am J Kidney Dis. (2011) 5:692-9. doi: 10.1053/j.ajkd.2010.11.029

45. Kher A. Tolvaptan in autosomal dominant polycystic kidney disease. $N$ Engl J Med. (2013) 368:1257-8.

46. Spital A. Tolvaptan in autosomal dominant polycystic kidney disease. N Engl J Med. (2013) 368:1257.

47. Jouret F, Krzesinski JM. Tolvaptan in autosomal dominant polycystic kidney disease. N Engl J Med. (2013) 368:1258-9.

48. Sexton DJ. Tolvaptan in autosomal dominant polycystic kidney disease. $N$ Engl J Med. (2013) 368:1258.

49. Vander Heiden MG, DeBerardinis RJ. Understanding the Intersections between Metabolism and Cancer Biology. Cell. (2017) 168:657-69. doi: 10.1016/j.cell.2016.12.039

50. Kuo IY, Brill AL, Lemos FO, Jiang JY, Falcone JL, Kimmerling $\mathrm{EP}$, et al. Polycystin 2 regulates mitochondrial $\mathrm{Ca}(2+)$ signaling, bioenergetics, and dynamics through mitofusin 2. Sci Signal. (2019) 12:aat7397. doi: 10.1126/scisignal.aat7397

51. Lin CC, Kurashige M, Liu Y, Terabayashi T, Ishimoto Y, Wang T, et al. A cleavage product of Polycystin-1 is a mitochondrial matrix protein that affects mitochondria morphology and function when heterologously expressed. Sci Rep. (2018) 8:2743. doi: 10.1038/s41598-018-20856-6

52. Ishimoto $Y$, Inagi $R$, Yoshihara D, Kugita $M$, Nagao $S$, Shimizu A, et al. Mitochondrial abnormality facilitates cyst formation in autosomal dominant polycystic kidney disease. Mol Cell Biol. (2017) 37:e0033717. doi: 10.1128/MCB.00337-17

53. Cassina L, Chiaravalli M, Boletta A. Increased mitochondrial fragmentation in polycystic kidney disease acts as a modifier of disease progression. FASEB J. (2020) 34:6493-507. doi: 10.1096/fj.201901739RR

54. Hajarnis S, Lakhia R, Yheskel M, Williams D, Sorourian M, Liu X, et al. microRNA-17 family promotes polycystic kidney disease progression through modulation of mitochondrial metabolism. Nat Commun. (2017) 8:14395. doi: 10.1038/ncomms14395

55. Blazer-Yost BL, Haydon J, Eggleston-Gulyas T, Chen JH, Wang $\mathrm{X}$, Gattone V, et al. Pioglitazone attenuates cystic burden in the PCK rodent model of polycystic kidney disease. PPAR Res. (2010) 2010:274376. doi: 10.1155/2010/274376

56. Yoshihara D, Kurahashi H, Morita M, Kugita M, Hiki Y, Aukema HM, et al. PPAR-gamma agonist ameliorates kidney and liver disease in an orthologous rat model of human autosomal recessive polycystic kidney disease. Am J Physiol Renal Physiol. (2011) 300:F465-74. doi: 10.1152/ajprenal.00 460.2010

57. Dai B, Liu, Y, Mei C, Fu L, Xiong X, Zhang Y, et al. Rosiglitazone attenuates development of polycystic kidney disease and prolongs survival in Han:SPRD rats. Clin Sci. (2010) 119:323-33. doi: 10.1042/CS20100113

58. Ma Y, Temkin SM, Hawkridge AM, Guo C, Wang W, Wang XY, et al. Fatty acid oxidation: an emerging facet of metabolic transformation in cancer. Cancer Lett. (2018) 435:92-100. doi: 10.1016/j.canlet.2018.08.006

59. Hensley CT, Wasti AT, DeBerardinis RJ. Glutamine and cancer: cell biology, physiology, and clinical opportunities. J Clin Invest. (2013) 123:36783684. doi: 10.1172/JCI69600

60. DeBerardinis RJ, Mancuso A, Daikhin E, Nissim I, Yudkoff M, Wehrli $\mathrm{S}$, et al. Beyond aerobic glycolysis: transformed cells can engage in 
glutamine metabolism that exceeds the requirement for protein and nucleotide synthesis. Proc Natl Acad Sci USA. (2007) 104:1934550. doi: 10.1073/pnas.0709747104

61. Hwang VJ, Kim J, Rand A, Yang C, Sturdivant S, Hammock B, et al. The cpk model of recessive PKD shows glutamine dependence associated with the production of the oncometabolite 2-hydroxyglutarate. Am J Physiol Renal Physiol. (2015) 309:F492-8. doi: 10.1152/ajprenal.00238.2015

62. Shim EH, Livi CB, Rakheja D, Tan J, Benson D, Parekh $\mathrm{V}$, et al. L-2-Hydroxyglutarate: an epigenetic modifier and putative oncometabolite in renal cancer. Cancer Discov. (2014) 4:1290-8. doi: 10.1158/2159-8290.CD-13-0696

63. Seeger-Nukpezah T, Geynisman DM, Nikonova AS, Benzing T, Golemis EA. The hallmarks of cancer: relevance to the pathogenesis of polycystic kidney disease. Nat Rev Nephrol. (2015) 11:515-34. doi: 10.1038/nrneph. 2015.46

64. Soomro I, Sun Y, Diggs L, i,. Z., Hatzivassiliou L, Thomas G, et al. Glutamine metabolism via glutaminase 1 in autosomal-dominant polycystic kidney disease. Nephrol Dial Transplant. (2018) 33:134353. doi: $10.1093 / \mathrm{ndt} / \mathrm{gfx} 349$

65. Lomelino CL, Andring JT, McKenna R, Kilberg MS. Asparagine synthetase: function, structure, and role in disease. J Biol Chem. (2017) 292:199528. doi: 10.1074/jbc.R117.819060

66. Zhang J, Fan J, Venneti S, Cross JR, Takagi T, Bhinder B, et al. Asparagine plays a critical role in regulating cellular adaptation to glutamine depletion. Mol Cell. (2014) 56:205-18. doi: 10.1016/j.molcel.2014.08.018

67. Baliga MM, Klawitter J, Christians U, Hopp K, Chonchol M, Gitomer BY, et al. Metabolic profiling in children and young adults with autosomal dominant polycystic kidney disease. Sci Rep. (2021) 11:6629. doi: 10.1038/s41598-021-84609-8

68. Trott JF, Hwang VJ, Ishimaru T, Chmiel KJ, Zhou JX, Shim K, et al. Arginine reprogramming in ADPKD results in argininedependent cystogenesis. Am J Physiol Renal Physiol. (2018) 315:F1855-68. doi: 10.1152/ajprenal.00025.2018

69. Patil MD, Bhaumik J, Babykutty S, Banerjee UC, Fukumura, D. Arginine dependence of tumor cells: targeting a chink in cancer's armor. Oncogene. (2016) 35:4957-72. doi: 10.1038/onc.2016.37

70. Wise DR, Thompson CB. Glutamine addiction: a new therapeutic target in cancer. Trends Biochem Sci. (2010) 35:427-33. doi: 10.1016/j.tibs.2010.05.003

71. Flowers EM, Sudderth J, Zacharias L, Mernaugh G, Zent R, DeBerardinis RJ, et al. Lkb1 deficiency confers glutamine dependency in polycystic kidney disease. Nat Commun. (2018) 9:814. doi: 10.1038/s41467-018-03036-y

72. Kahveci AS, Barnatan TT, Kahveci A, Adrian AE, Arroyo J, Eirin A, et al. Oxidative stress and mitochondrial abnormalities contribute to decreased endothelial nitric oxide synthase expression and renal disease progression in early experimental polycystic kidney disease. Int J Mol Sci. (2020) 21:1194. doi: 10.3390/ijms21061994

73. Nowak KL, Farmer H, Cadnapaphornchai MA, Gitomer B, Chonchol, M. Vascular dysfunction in children and young adults with autosomal dominant polycystic kidney disease. Nephrol Dial Transplant. (2017) 32:3427. doi: $10.1093 / \mathrm{ndt} / \mathrm{gfw} 013$

74. Klawitter J, Reed-Gitomer BY, McFann K, Pennington A, Klawitter J, Abebe KZ, et al. Endothelial dysfunction and oxidative stress in polycystic kidney disease. Am J Physiol Renal Physiol. (2014) 307:F1198206. doi: 10.1152/ajprenal.00327.2014

75. Cyr AR, Huckaby LV, Shiva SS, Zuckerbraun BS. Nitric oxide and endothelial dysfunction. Crit Care Clin. (2020) 36:307-21. doi: 10.1016/j.ccc.2019.12.009

76. Verdoodt A, Honore PM, Jacobs R, De Waele HD. Do statins induce or protect from acute kidney injury and chronic kidney disease: an update review in 2018. J Transl Int Med. (2018) 6:21-5. doi: 10.2478/jtim-2018-0005

77. Zheng Z, Jayaram R, Jiang L, Emberson J, Zhao Y, Du L, et al. Perioperative rosuvastatin in cardiac surgery. N Engl J Med. (2016) 374:174453. doi: 10.1056/NEJMoa 1507750

78. Klawitter J, McFann K, Pennington AT, Wang W, Klawitter J, Christians $\mathrm{U}$, et al. Pravastatin therapy and biomarker changes in children and young adults with autosomal dominant polycystic kidney disease. Clin J Am Soc Nephrol. (2015) 10:1534-41. doi: 10.2215/CJN.11331114

79. Brosnahan GM, Abebe KZ, Rahbari-Oskoui FF, Patterson CG, Bae $\mathrm{KT}$, Schrier RW, et al. Effect of statin therapy on the progression of autosomal dominant polycystic kidney disease. A secondary analysis of the HALT PKD trials. Curr Hypertens Rev. (2017) 13:109-20. doi: 10.2174/1573402113666170427142815

80. Steuer R, Gross T, Selbig J, Blasius B. Structural kinetic modeling of metabolic networks. Proc Natl Acad Sci USA. (2006) 103:11868-73. doi: 10.1073/pnas.0600013103

81. Saa PA, Nielsen LK. Formulation, construction and analysis of kinetic models of metabolism: A review of modelling frameworks. Biotechnol Adv. (2017) 35:981-1003. doi: 10.1016/j.biotechadv.09005

82. Keizer J. Statistical Thermodynamics of Nonequilibrium Processei. New York, NY; Berlin; Heidelberg; London; Paris; Tokyo: Springeí Verlag (1989).

83. Michaelis L, Menten M, Johnson KA, Goody R. The original Michaelis constant: translation of the 1913 Michaelis-Menten paper. Biochemistry. (2011) 50:8264-9. doi: 10.1021/bi201284u

84. Cornish-Bowden A. Fundamentals of Enzyme Kinetics (1979).

85. Savageau MA. Biochemical systems analysis. I Some mathematical properties of the rate law for the component enzymatic reactions. J Theor Biol. (1969) 25:365-9. doi: 10.1016/s0022-5193(69)80026-3

86. Orth JD, Thiele I, Palsson BO. What is flux balance analysis? Nat Biotechnol. (2010) 28:245-8. doi: 10.1038/nbt.1614

87. Pagliarini R, Castello R, Napolitano F, Borzone R, Annunziata P, Mandrile $\mathrm{G}$, et al. In silico modeling of liver metabolism in a human disease reveals a key enzyme for histidine and histamine homeostasis. Cell Rep. (2016) 15:2292-300. doi: 10.1016/j.celrep.2016.05.014

88. Pagliarini R, di Bernardo, D. A genome-scale modeling approach to study inborn errors of liver metabolism: toward an in silico patient. J Comput Biol. (2016). 20:383-97. doi: 10.1089/cmb.2012.0276

89. Pagliarini R, Boletta, A. In SILICO simulations predict a causative link between increased glycolysis and metabolic reprogramming in autosomal dominant polycystic kidney disease. In: 2019 IEEE Conference on Computational Intelligence in Bioinformatics and Computational Biology (Siena). (2019). p. 1-9. doi: 10.1109/CIBCB.2019.8791243

90. Rahimmanesh I, Fatehi, R. Systems biology approaches toward autosomal dominant polycystic kidney disease (ADPKD). Clin Transl Med. (2020) 9:1. doi: 10.1186/s40169-019-0254-5

91. Kocyigit I, Eroglu E, Kaynar AS, Kocer D, Kargi S, Zararsiz G, et al. The association of endothelin-1 levels with renal survival in polycystic kidney disease patients. J Nephrol. (2019) 32:83-91. doi: 10.1007/s40620-018-0514-2

92. Chang MY, Ong AC. M. Endothelin in polycystic kidney disease. Contrib Nephrol. (2011) 172:200-9. doi: 10.1159/000328701

93. Liu D, Huo Y, Chen S, Xu D, Yang B, Xue C, et al. Identification of key genes and candidated pathways in human autosomal dominant polycystic kidney disease by bioinformatics analysis. Kidney Blood Press Res. (2019) 44:533-52. doi: 10.1159/000500458

94. Woo YM, Kim DY, Koo NJ, Kim YM, Lee S, Ko JY, et al. Profiling of miRNAs and target genes related to cystogenesis in ADPKD mouse models. Sci Rep. (2017) 7:14151. doi: 10.1038/s41598-017-14083-8

95. Pandey P, Qin S, Ho J, Zhou J, Kreidberg JA. Systems biology approach to identify transcriptome reprogramming and candidate microRNA targets during the progression of polycystic kidney disease. BMC Syst Biol. (2011) 5:56. doi: 10.1186/1752-0509-5-56

96. Patel V, Williams D, Hajarnis S, Hunter R, Pontoglio M, Somlo S, et al. miR-17 92 miRNA cluster promotes kidney cyst growth in polycystic kidney disease. Proc Natl Acad Sci USA. (2013) 110:1076570. doi: 10.1073/pnas.1301693110

97. Lakhia R, Yheskel M, Flaten A, Ramalingam H, Aboudehen K, Ferre $S$, et al. Interstitial microRNA miR-214 attenuates inflammation and polycystic kidney disease progression. JCI Insight. (2020) 5:133785. doi: 10.1172/jci.insight. 133785

98. Piontek K, Menezes LF, Garcia-Gonzalez MA, Huso DL, Germino GG. A critical developmental switch defines the kinetics of kidney cyst formation after loss of Pkd1. Nat Med. (2007) 13:1490-5. doi: 10.1038/nm1675

99. Menezes LF, Zhou F, Patterson AD, Piontek KB, Krausz KW, Gonzalez FJ, et al. Network analysis of a Pkd1-mouse model of autosomal dominant polycystic kidney disease identifies HNF4alpha as a disease modifier. PLoS Genet. (2012) 8:e1003053. doi: 10.1371/journal.pgen.1003053

100. Aboudehen K, Farahani S, Kanchwala M, Chan SC, Avdulov S, Mickelson A, et al. Long noncoding RNA Hoxb3os is dysregulated in autosomal dominant 
polycystic kidney disease and regulates mTOR signaling. J Biol Chem. (2018) 293:9388-98. doi: 10.1074/jbc.RA118.001723

101. Lantinga-van Leeuwen IS, Dauwerse JG, Baelde HJ, Leonhard WN, van de Wal A, Ward CJ, et al. Lowering of Pkd1 expression is sufficient to cause polycystic kidney disease. Hum Mol Genet. (2004) 13:3069-77. doi: $10.1093 / \mathrm{hmg} / \mathrm{ddh} 336$

102. Rossetti S, Kubly VJ, Consugar MB, Hopp K, Roy S, Horsley SW, et al. Incompletely penetrant PKD1 alleles suggest a role for gene dosage in cyst initiation in polycystic kidney disease. Kidney Int. (2009) 75:848-55. doi: $10.1038 / \mathrm{ki} .2008 .686$

103. Hopp K, Ward CJ, Hommerding CJ, Nasr SH, Tuan HF, Gainullin VG, et al. Functional polycystin-1 dosage governs autosomal dominant polycystic kidney disease severity. J Clin Invest. (2012) 122:4257-73. doi: $10.1172 /$ JCI64313

104. Harris PC, Torres VE. Genetic mechanisms and signaling pathways in autosomal dominant polycystic kidney disease. J Clin Invest. (2014) 124:2315-24. doi: 10.1172/JCI72272

105. Torres VE, Chapman AB, Devuyst O, Gansevoort RT, Grantham JJ, Higashihara E, et al. Tolvaptan in patients with autosomal dominant polycystic kidney disease. N Engl J Med. (2012) 367:2407-18. doi: 10.1056/NEJMoa1205511

106. Torres VE, Chapman AB, Devuyst O, Gansevoort RT, Perrone RD, Koch G, et al. Tolvaptan in later-stage autosomal dominant polycystic kidney disease. N Engl J Med. (2017) 377:1930-42. doi: 10.1056/NEJMoa1710030

107. Lian X, Zhao J, Wu X, Zhang Y, Li Q, Lin S, et al. The changes in glucose metabolism and cell proliferation in the kidneys of polycystic kidney disease mini-pig models. Biochem Biophys Res Commun. (2017) 488:37481. doi: 10.1016/j.bbrc.2017.05.060

108. Distefano G, Boca M, Rowe I, Wodarczyk C, Ma L, Piontek KB, et al. Polycystin-1 regulates extracellular signal-regulated kinase-dependent phosphorylation of tuberin to control cell size through mTOR and its downstream effectors S6K and 4EBP1. Mol Cell Biol. (2009) 29:235971. doi: 10.1128/MCB.01259-08

109. Shillingford JM, Piontek KB, Germino GG, and Weimbs, T. Rapamycin ameliorates PKD resulting from conditional inactivation of Pkd1. J Am Soc Nephrol. (2010) 21:489-97. doi: 10.1681/ASN.2009040421

110. Shibazaki S, Yu Z, Nishio S, Tian X, Thomson RB, Mitobe M, et al. Cyst formation and activation of the extracellular regulated kinase pathway after kidney specific inactivation of Pkd1. Hum Mol Genet. (2008) 17:150516. doi: $10.1093 / \mathrm{hmg} / \mathrm{ddn} 039$

111. Myint TM, Rangan GK, Webster AC. Treatments to slow progression of autosomal dominant polycystic kidney disease: systematic review and meta-analysis of randomized trials. Nephrology. (2014) 19:21726. doi: $10.1111 /$ nep. 12211

112. Dirksen ML, Crouch RJ. Selective inhibition of RNase H by dextran. J Biol Chem. (1981) 256:11569-73.

113. Crooke ST. Molecular mechanisms of antisense oligonucleotides. Nucleic Acid Ther. (2017) 27:70-7. doi: 10.1089/nat.2016.0656

114. Crooke ST, Witztum JL, Bennett CF, Baker BF. RNA-targeted therapeutics. Cell Metab. (2018) 27:714-39. doi: 10.1016/j.cmet.2018.03.004

115. Crooke ST, Liang XH, Baker BF, Crooke RM. Antisense technology: a review. J Biol Chem. (2021) 296:100416. doi: 10.1016/j.jbc.2021.100416

116. Ravichandran K, Zafar I, He Z, Doctor RB, Moldovan R, Mullick AE, et al. An mTOR anti-sense oligonucleotide decreases polycystic kidney disease in mice with a targeted mutation in Pkd2. Hum Mol Genet. (2014) 23:491931. doi: $10.1093 / \mathrm{hmg} / \mathrm{ddu} 208$

117. Nowak KL, Wang W, Farmer-Bailey H, Gitomer B, Malaczewski M, Klawitter J, et al. Vascular dysfunction, oxidative stress, and inflammation in autosomal dominant polycystic kidney disease. Clin J Am Soc Nephrol. (2018) 13:1493-501. doi: 10.2215/CJN.05850518

118. Klawitter J, Klawitter J, McFann K, Pennington AT, Abebe KZ, Brosnahan G, et al. Bioactive lipid mediators in polycystic kidney disease. J Lipid Res. (2014) 55:1139-49. doi: 10.1194/jlr.P042176

119. Culliford A, Phagura N, Sharif, A. Autosomal dominant polycystic kidney disease is a risk factor for posttransplantation diabetes mellitus: an updated systematic review and meta-analysis. Transplant Direct. (2020) 6:e553. doi: 10.1097/TXD.0000000000000989
120. Ellison DH, Ingelfinger JR. A quest-halting the progression of autosomal dominant polycystic kidney disease. N Engl J Med. (2014) 371:232931. doi: 10.1056/NEJMe1412586

121. Saigusa T, Dang Y, Mullick AE, Yeh ST, Zile MR, Baicu CF, et al. Suppressing angiotensinogen synthesis attenuates kidney cyst formation in a Pkd1 mouse model. FASEB J. (2016) 30:370-9. doi: 10.1096/fj.15-279299

122. Fitzgibbon WR, Dang Y, Bunni MA, Baicu CF, Zile MR, Mullick AE, et al. Attenuation of accelerated renal cystogenesis in Pkd1 mice by reninangiotensin system blockade. Am J Physiol Renal Physiol. (2018) 314:F2108. doi: 10.1152/ajprenal.00389.2017

123. Ravichandran K, Ozkok A, Wang Q, Mullick AE, Edelstein CL. Antisensemediated angiotensinogen inhibition slows polycystic kidney disease in mice with a targeted mutation in Pkd2. Am J Physiol Renal Physiol. (2015) 308:F349-57. doi: 10.1152/ajprenal.00478.2014

124. Yheskel M, Lakhia R, Cobo-Stark P, Flaten A, Patel, V. AntimicroRNA screen uncovers miR-17 family within miR-17 92 cluster as the primary driver of kidney cyst growth. Sci Rep. (2019) 9:1920. doi: 10.1038/s41598-019-38566-y

125. Lee EC, Valencia T, Allerson C, Schairer A, Flaten A, Yheskel M, et al. Discovery and preclinical evaluation of anti-miR-17 oligonucleotide RGLS4326 for the treatment of polycystic kidney disease. Nat Commun. (2019) 10:4148. doi: 10.1038/s41467-019-11918-y

126. Mi Z, Song Y, Cao X, Lu Y, Liu Z, Zhu X, et al. Super-enhancerdriven metabolic reprogramming promotes cystogenesis in autosomal dominant polycystic kidney disease. Nat Metab. (2020) 2:717-31. doi: 10.1038/s42255-020-0227-4

127. Chiaravalli M, Rowe I, Mannella V, Quilici G, Canu T, Bianchi V, et al. 2Deoxy-d-Glucose Ameliorates PKD Progression. J Am Soc Nephrol. (2016) 27:1958-69. doi: 10.1681/ASN.2015030231

128. Magistroni R, Boletta, A. Defective glycolysis and the use of 2deoxy-D-glucose in polycystic kidney disease: from animal models to humans. J Nephrol. (2017) 30:511-9. doi: 10.1007/s40620-0170395-9

129. Ingram DK, Roth GS. Glycolytic inhibition as a strategy for developing calorie restriction mimetics. Exp Gerontol. (2011) 46:148-54. doi: 10.1016/j.exger.2010.12.001

130. Carney EF. Ketosis slows the progression of PKD. Nat Rev Nephrol. (2020) 16:1. doi: 10.1038/s41581-019-0226-4

131. Warner G, Hein KZ, Nin V, Edwards M, Chini CC, Hopp K, et al. Food restriction ameliorates the development of polycystic kidney disease. J Am Soc Nephrol. (2016) 27:1437-47. doi: 10.1681/ASN.2015020132

132. Kipp KR, Rezaei M, Lin L, Dewey EC, Weimbs T. A mild reduction of food intake slows disease progression in an orthologous mouse model of polycystic kidney disease. Am J Physiol Renal Physiol. (2016) 310:F72631. doi: 10.1152/ajprenal.00551.2015

133. Ramalingam H, Kashyap S, Cobo-Stark P, Flaten A, Chang CM, Hajarnis S, et al. A methionine-Mettl3-N(6)-methyladenosine axis promotes polycystic kidney disease. Cell Metab. (2021) 33:1234-47.e7. doi: 10.1016/j.cmet.2021.03.024

134. Torres VE. Pro: tolvaptan delays the progression of autosomal dominant polycystic kidney disease. Nephrol Dial Transplant. (2019) 34:30-4. doi: 10.1093/ndt/gfy297

135. Flanagan JU, Yosaatmadja Y, Teague RM, Chai MZ, Turnbull AP, Squire CJ. Crystal structures of three classes of non-steroidal anti-inflammatory drugs in complex with aldo-keto reductase 1C3. PLoS ONE. (2012) 7:e43965. doi: 10.1371/journal.pone.0043965

136. Aziz N, Maxwell MM, Brenner BM. Coordinate regulation of 11 beta-HSD and Ke 6 genes in cpk mouse: implications for steroid metabolic defect in PKD. Am J Physiol. (1994) 267:F791-7. doi: 10.1152/ajprenal.1994.267.5.F791

137. Lakhia R, Yheskel M, Flaten A, Quittner-Strom EB, Holland WL, Patel, V. PPARalpha agonist fenofibrate enhances fatty acid beta-oxidation and attenuates polycystic kidney and liver disease in mice. Am J Physiol Renal Physiol. (2018) 314:F122-31. doi: 10.1152/ajprenal.00352.2017

138. Srivastava AK, Jaganathan S, Stephen L, Hollingshead MG, Layhee A, Damour E, et al. Effect of a smac mimetic (TL32711, Birinapant) on the apoptotic program and apoptosis biomarkers examined with validated 
multiplex immunoassays fit for clinical use. Clin Cancer Res. (2016) 22:100010. doi: 10.1158/1078-0432.CCR-14-3156

139. Fan LX, Zhou X, Sweeney WE Jr, Wallace DP, Avner ED, Grantham JJ, et al. Smac-mimetic-induced epithelial cell death reduces the growth of renal cysts. J Am Soc Nephrol. (2013) 24:2010-22. doi: 10.1681/ASN.2013020176

140. Bowman BT, Rosner MH. Lixivaptan - an evidence-based review of its clinical potential in the treatment of hyponatremia. Core Evid. (2013) 8:4756. doi: 10.2147/CE.S36744

141. Woodhead JL, Pellegrini L, Shoda LK. M., and Howell BA. Comparison of the hepatotoxic potential of two treatments for autosomal-dominant polycystic kidney diseaseusing quantitative systems toxicology modeling. Pharm Res. (2020) 37:24. doi: 10.1007/s11095-019-2726-0

142. Fedeles SV, Tian X, Gallagher AR, Mitobe M, Nishio S, Lee SH, et al. A genetic interaction network of five genes for human polycystic kidney and liver diseases defines polycystin-1 as the central determinant of cyst formation. Nat Genet. (2011) 43:639-47. doi: 10.1038/ng.860

143. Tan M, Wettersten HI, Chu K, Huso DL, Watnick T, Friedlander S, et al. Novel inhibitors of nuclear transport cause cell cycle arrest and decrease cyst growth in ADPKD associated with decreased CDK4 levels. Am J Physiol Renal Physiol. (2014) 307:F1179-86. doi: 10.1152/ajprenal.00 406.2014

144. Namli S, Oflaz H, Turgut F, Alisir S, Tufan F, Ucar A, et al. Improvement of endothelial dysfunction with simvastatin in patients with autosomal dominant polycystic kidney disease. Ren Fail. (2007) 29:559. doi: $10.1080 / 08860220601038892$

145. Olson RJ, Hopp K, Wells H, Smith JM, Furtado J, Constans MM, et al. Synergistic genetic interactions between Pkhdl and Pkdl result in an ARPKD-like phenotype in murine models. J Am Soc Nephrol. (2019) 30:2113-27. doi: 10.1681/ASN.2019020150

146. Koupepidou P, Felekkis KN, Kranzlin B, Sticht C, Gretz N, and Deltas, C. Cyst formation in the PKD2 (1-703) transgenic rat precedes deregulation of proliferation-related pathways. BMC Nephrol. (2010) 11:23. doi: 10.1186/1471-2369-11-23

147. Felekkis KN, Koupepidou P, Kastanos E, Witzgall R, Bai CX, Tsiokas L, et al. Mutant polycystin-2 induces proliferation in primary rat tubular epithelial cells in a STAT-1/p21-independent fashion accompanied instead by alterations in expression of p57KIP2 and Cdk2. BMC Nephrol. (2008) 9:10. doi: 10.1186/1471-2369-9-10

148. Pandey P, Brors B, Srivastava PK, Bott A, Boehn SN, Groene HJ, et al. Microarray-based approach identifies microRNAs and their target functional patterns in polycystic kidney disease. BMC Genomics. (2008) 9:624. doi: 10.1186/1471-2164-9-624

149. Chen WC, Tzeng YS, Li, H. Gene expression in early and progression phases of autosomal dominant polycystic kidney disease. BMC Res Notes. (2008) 1:131. doi: 10.1186/1756-0500-1-131

150. Allen E, Piontek KB, Garrett-Mayer E, Garcia-Gonzalez M, Gorelick KL, and Germino GG. Loss of polycystin-1 or polycystin-2 results in dysregulated apolipoprotein expression in murine tissues via alterations in nuclear hormone receptors. Hum Mol Genet. (2006) 15:11-21. doi: $10.1093 / \mathrm{hmg} / \mathrm{ddi} 421$

151. Kugita M, Nishii K, Morita M, Yoshihara D, Kowa-Sugiyama H, Yamada K, et al. Global gene expression profiling in early-stage polycystic kidney disease in the Han:SPRD Cy rat identifies a role for RXR signaling. Am J Physiol Renal Physiol. (2011) 300:F177-88. doi: 10.1152/ajprenal.00470.2010

152. Ameku T, Taura D, Sone M, Numata T, Nakamura M, Shiota F, et al. Identification of MMP1 as a novel risk factor for intracranial aneurysms in ADPKD using iPSC models. Sci Rep. (2016) 6:30013. doi: 10.1038/srep30013

153. Cruz NM, Song X, Czerniecki SM, Gulieva RE, Churchill AJ, Kim YK, et al. Organoid cystogenesis reveals a critical role of microenvironment in human polycystic kidney disease. Nat Mater. (2017) 16:1112-9. doi: 10.1038/nmat4994

154. Sun Y, Liu Z, Cao X, Lu Y, He C, Liu J, et al. Activation of P-TEFb by cAMPPKA signaling in autosomal dominant polycystic kidney disease. Sci $A d v$. (2019) 5:eaaw3593. doi: 10.1126/sciadv.aaw3593

155. Hogan MC, Bakeberg JL, Gainullin VG, Irazabal MV, Harmon AJ, Lieske JC. McCormick DJ, et al. Identification of biomarkers for PKD1 using urinary exosomes. J Am Soc Nephrol. (2015) 26:166170. doi: 10.1681/ASN.2014040354
156. Streets AJ, Magayr TA, Huang L, Vergoz L, Rossetti S, Simms RJ, et al. Parallel microarray profiling identifies ErbB4 as a determinant of cyst growth in ADPKD and a prognostic biomarker for disease progression. Am J Physiol Renal Physiol. (2017) 312:F577-88. doi: 10.1152/ajprenal.00607.2016

157. Kunnen SJ, Malas TB, Semeins CM, Bakker AD, Peters DJM. Comprehensive transcriptome analysis of fluid shear stress altered gene expression in renal epithelial cells. J Cell Physiol. (2018) 233:3615-28. doi: 10.1002/jcp.26222

158. Barrett T, Wilhite SE, Ledoux P, Evangelista C, Kim IF, Tomashevsky M, et al. NCBI GEO: archive for functional genomics data sets-update. Nucleic Acids Res. (2013) 41:D991-5. doi: 10.1093/nar/gks1193

159. Haug K, Cochrane K, Nainala VC, Williams M, Chang J, Jayaseelan KV, et al. MetaboLights: a resource evolving in response to the needs of its scientific community. Nucleic Acids Res. (2020) 48:D440-4. doi: 10.1093/nar/gkz1019

160. Brazma A, Kapushesky M, Parkinson H, Sarkans U, Shojatalab M. Data storage and analysis in ArrayExpress. Methods Enzymol. (2006) 411:37086. doi: 10.1016/S0076-6879(06)11020-4

161. Perez-Riverol Y, Csordas A, Bai J, Bernal-Llinares M, Hewapathirana S, Kundu DJ, et al. The PRIDE database and related tools and resources in 2019: improving support for quantification data. Nucleic Acids Res. (2019) 47:D442-50. doi: 10.1093/nar/gky1106

162. Shaar-Moshe L, Hubner S, Peleg, Z. Identification of conserved droughtadaptive genes using a cross-species meta-analysis approach. BMC Plant Biol. (2015) 15:111. doi: 10.1186/s12870-015-0493-6

163. Sweeney TE, Haynes WA, Vallania F, Ioannidis JP, Khatri, P. Methods to increase reproducibility in differential gene expression via meta-analysis. Nucleic Acids Res. (2017) 45:e1. doi: 10.1093/nar/gkw797

164. Chatterjee S, Verma SP, Pandey P. Profiling conserved biological pathways in Autosomal Dominant Polycystic Kidney Disorder (ADPKD) to elucidate key transcriptomic alterations regulating cystogenesis: A cross-species metaanalysis approach. Gene. (2017) 627:434-50. doi: 10.1016/j.gene.2017.06.059

165. co-chairs EAF, Harris T, Sandford R, EAF members participants Roundtable. European ADPKD Forum multidisciplinary position statement on autosomal dominant polycystic kidney disease care: European ADPKD Forum and Multispecialist Roundtable participants. Nephrol Dial Transplant. (2018) 33:563-73. doi: 10.1093/ndt/gfx327

166. De Rechter S, Bockenhauer D, Guay-Woodford LM, Liu I, Mallett AJ, Soliman NA, et al. ADPedKD: a global online platform on the management of children with ADPKD. Kidney Int Rep. (2019) 4:1271-84. doi: 10.1016/j.ekir.2019.05.015

167. Schaefer F, Mekahli D, Emma F, Gilbert RD, Bockenhauer D, Cadnapaphornchai MA, et al. Tolvaptan use in children and adolescents with autosomal dominant polycystic kidney disease: rationale and design of a two-part, randomized, double-blind, placebo-controlled trial. Eur J Pediatr. (2019) 178:1013-21. doi: 10.1007/s00431-019-03384-x

168. Carriazo S, Perez-Gomez MV, Cordido A, Garcia-Gonzalez MA, Sanz AB, Ortiz A, et al. Dietary care for ADPKD patients: current status and future directions. Nutrients. (2019) 11:1576. doi: 10.3390/nu11071576

Conflict of Interest: CP is a co-inventor on the use of metabolic inhibitors in Polycystic Kidney Disease.

The remaining author declares that the research was conducted in the absence of any commercial or financial relationships that could be construed as a potential conflict of interest.

Publisher's Note: All claims expressed in this article are solely those of the authors and do not necessarily represent those of their affiliated organizations, or those of the publisher, the editors and the reviewers. Any product that may be evaluated in this article, or claim that may be made by its manufacturer, is not guaranteed or endorsed by the publisher.

Copyright (c) 2021 Pagliarini and Podrini. This is an open-access article distributed under the terms of the Creative Commons Attribution License (CC BY). The use, distribution or reproduction in other forums is permitted, provided the original author(s) and the copyright owner(s) are credited and that the original publication in this journal is cited, in accordance with accepted academic practice. No use, distribution or reproduction is permitted which does not comply with these terms. 